\title{
Unveiling the Intellectual Origins of Social Media-based Innovation: Insights from a Bibliometric Approach
}

\begin{abstract}
This article uses a bundle of bibliometric and text-mining techniques to provide a systematic assessment of the intellectual core of the Social Media-based innovation research field. The goal of this study is to identify main research areas, understand the current state of development and suggest potential future directions by analysing co-citations from 155 papers published between 2003 and 2013 in the most influential academic journals. The main clusters have been identified, mapped, and labelled. Their most active areas on this topic and the most influential and co-cited papers have been identified and described. Also, intra- and inter-cluster knowledge base diversity has been assessed by using indicators stemming from the domains of Information Theory and Biology. A t-test has been performed to assess the significance of the inter-cluster diversity. Five co-existing research streams shaping the research field under investigation have been identified and characterized.
\end{abstract}

Keywords: Social Media, innovation, bibliometric analysis, content analysis, diversity analysis

JEL codes: O32, M15 


\section{Introduction}

The term Social Media denotes highly interactive platforms via which individuals and communities share, co-create, discuss, and modify user-generated content (Kaplan and Haenlein, 2010). Examples of Social Media platforms include blogs (Blogger, Wordpress), microblogs (Twitter), collaborative wiki-projects (Wikipedia), forums (Harley Davidson user groups, Microsoft MSDN), professional networking sites (LinkedIn, Xing), and social networks (Facebook, Google+) (Kaplan and Haenlein, 2010; Cortizo et al., 2011). While the aforementioned applications are dominated by text, other applications are dedicated to other forms of media, like photographs (Flickr, Picasa), videos (YouTube, Vimeo) or music tracks (last.fm, ccMixter). Social Media today have also expanded into virtual worlds (Second Life) and online gaming (World of Warcraft, Farmville). A new field in Social Media applications is based on the usage of mobile data and the rapid adoption of smartphones (Nomad Social Networks, Foursquare).

These applications have been used by both small and large firms to improve internal operations and collaborate with customers, business partners, and suppliers in new ways (see e.g. Martini et al., 2014). According to Culnan and co-authors (2010), companies engage in Social Media applications to support a variety of activities, including marketing (e.g., to build customer loyalty and/or increase customer retention); sales (e.g., to increase revenues); customer service/support (e.g., to increase customer satisfaction); and product development and innovation (e.g., to increase fit to market).

This paper focuses on the use of Social Media by companies for product development and innovation. Most of the literature agrees that the advent of Social Media - coupled with the paradigm shift from closed to open innovation (Chesbrough, 2003) - has changed the landscape of innovation for companies. In a variety of ways, Social Media allow for the involvement of external actors in innovation processes on an extended basis and with limited costs. Regardless of their size and location, this makes open innovation a real opportunity for firms, but not without presenting specific risks and challenges (Kaplan and Haenlein, 2010). Many organizations find it challenging to integrate Social Media effectively into organizational innovation practices because Social Media are primarily complex, informal and episodic (He and Wang, 2015).

Despite difficulties, the literature provides clear examples of companies that were able to seize this opportunity by changing their business model to open their innovation processes and leverage Social Media. The case of Lego is emblematic as they were able to turn threat into opportunity; they allowed customers to modify their products motor's software after it was hacked to make unauthorized modifications. Results included a middle-school curriculum using Legos to teach children robotics (Hienerth et al., 2011; Chesbrough, 2011).

A key driver of value added by Social Media is the formation of online customer communities (Piller et al., 2012). However, beyond attracting a critical mass of participants who consistently engage with the firm and/or other community members, firms must also develop dedicated processes in order to benefit from customer-generated content (see e.g. Martini et al., 2013). Without this second condition, Social Media do not create value for a firm (Culnan et al., 2010). Today, online communities have become central to the product or service development process. Examples range from sports equipment (Füller et al., 2007) to the games industry (Jeppesen and Molin, 2003) and from the catering industry (Gallagher and Ransbotham, 2010) to the PC industry (Di Gangi and Wasko, 2009; Di Gangi et al., 2010). Social Media change the role of customers. They are not only the final recipient of a firm's product or service; they become co-creators as well as a means of communication (that can either promote or even boycott products and services). In this context, Social Media represent both a locus for customers to express their opinion about a firm's products or services and a place where new products or services can be created.

However, the literature is fast-growing and despite few qualitative reviews are providing evidence on specific characteristics of the topic (Khan, 2013; Effing and Spil, 2016; Bolton et al., 2013; Ngai et al., 2015a, 2015b; Gan and Wang, 2015), they are silent on the intersection between Social Media and Innovation. A brief overview of these reviews will reveal the gap we want to address. 
Khan (2013) focuses on Social Media-based Systems (SMS), pinpointing the specific Information System/Computer Science research stream. Indeed, the author defines SMS as the application of a wider range of social software and social media phenomenon in organizational and non-organization context to facilitate every day interactions (p. 159).' Author uses both qualitative and quantitative approaches. His selection concerns the Computer Science Information Systems domain in the Web of Science (WoS) database only. Our selected sample is different in that our focus is on the Innovation side of the Social Media phenomenon, and we did not limit ourselves to WoS. Effing and Spil (2016) focus on the assessment of Social Media strategies. Their review - qualitative in nature - is mixed with interviews and retrieve the 66 key papers from both Scopus and WoS. They advance a Social Media "strategy cone" on the basis of some key elements such as target audience, channel choice, goals, resources, policies, monitoring, content activities. Instead, we advance a comprehensive identification and characterization of the most relevant inputs, processes, and outputs; accordingly, their insights would target the Firms' motivations and antecedents (Input) as a way of getting better Firms' performance and changes (Output). Our sample is still larger and more comprehensive. Bolton et al. (2013) focus on the way(s) Generation Y people use Social Media, providing implications at individual, firm, and societal levels. Their review is exclusively qualitative in nature and provides the reader with an interesting framework which would target our Input section (Users' motivations and antecedents), Process section (Users' behaviours; Firms' behaviours), and Output section (Firms' performance and/or changes). It also deals with environmental factors which we call External Contingency Factors (i.e. economic environment, technological environment, cultural environment, legal/political environment, etc.). Ngai et al. (2015a) carry out a qualitative literature review with 'the aim of developing a conceptual framework to explain how social media applications are supported by various social media tools and technologies and underpinned by a set of personal and social behaviour theories or models (p. 769).' Their focus is on what we labelled the Social platforms' characteristics and aims (Process section) in that authors explore the potential of a wide range of Social Media applications in the Marketing, Customer Relationships Management, Knowledge sharing, collaborative activities, organization communications, education and training domains. They also go through the different technologies at their basis (e.g., social bookmarking sites, virtual/online communities, media sharing sites, etc.). Ngai et al. (2015b) perform a systematic and structured literature review, by scrutinizing 46 articles on Social Media research, for a period spanning from 2002 to 2011. Their review is qualitative in nature and aims at generating a causal-chain framework based on antecedents, mediators, moderators, and outcomes. A partial overlapping is visible when it comes to consider their Antecedents and Outcomes sections and our Inputs and Outputs sections. However, our sample is larger and the review is more robust in that it starts with an objective selection of the sources and investigates their references. Furthermore, their focus is quite different in that they unveil which theories and models are used in social media research. On our side, we wants to show which research streams originated the field; and each research stream is necessarily described by a bundle of theories and models. Finally, Gan and Wang (2015) provide the reader with a study aiming at unveiling the intellectual origins of the social media research in China, by considering a time span from 2006 to 2013. They apply both a bibliometric and co-word analysis to a set of 3,178 papers downloaded from the China Academic Journals Full-text Database. Clusters are generated by using the most relevant keywords and a two-dimensional map was created in order to map the research topics on social media in China. A social network analysis was carried out on the basis of a co-occurrence matrix built on keywords occurrence frequencies. No treatment of the references of the 3,178 papers was implemented; also, authors exclusively focus on the Chinese context in a limited period (2006-2013).

Extensive literature on Social Media-based innovation exists outside the organizational context. An example of this is so-called bottom-up online communities, which develop around a common passion or love of a brand (see e.g., Füller et al., 2007). In this paper, we aim to provide an extensive analysis of the research streams which, over time, pave the way to the Social Media-based innovation, i.e. innovation developed through Web 2.0 applications. These applications are heterogeneous and include innovation contests (e.g., Piller and Walcher, 2006; Ebner et al., 2009; Bullinger et al., 2010; Füller, 
2010; Hutter et al., 2011), online toolkits (e.g., Von Hippel and Katz, 2002; Franke and Piller, 2003; Jeppesen, 2005), and varying types of communities (e.g., Franke and Shah, 2003; Füller et al., 2008).

Then, the idea of this paper is to unveil the origins of Social Media-based innovation by analysing the references in the most important academic contributions. They discuss Social Media applications to support new product development and innovation, yet they do not limit this to use of Social Media by firms. Our strategy aims at analysing a larger number of journals and articles, from a comprehensive selection of databases. We use a mixed strategy (objective and subjective) in terms of methodological approaches in order to assure robustness and replicability. A preliminary Input-Process-Output (IPO) framework is described by identifying the state-of-the-art. Finally, a comprehensive description of the originating research streams is provided by linking them to the elements of the IPO framework. The existing contributions on the topic may be considered as deep (and complementary) explorations of specific sections of our IPO framework.

The paper unfolds as follows. Section 2 presents the methodology used for the systematic analysis. Section 3 describes results and introduces the originating research fields. Section 4 provides the discussion on how the originating research streams shaped the intellectual core. Section 5 illustrates the main conclusions and Section 6 shows the limitations and avenues for future research.

\section{Methodology}

The methodology behind this research entails a four-step analysis: 1) data collection, and identification and interpretation of the intellectual core (McCain, 1990; Small, 2003; David and Han, 2004); 2) bibliometric analysis (Document Co-citation Analysis) of the references belonging to the intellectual core with the identification of the main clusters using VOSviewer 1.6.1 (Appio et al., 2014; Chen et al., 2010; Van Eck and Waltman, 2010); 3) content analysis of the identified clusters by using VOSviewer 1.6.1 (Van Eck and Waltman, 2011); 4) diversity analysis of the identified clusters by calculating the Shannon-Wiener diversity index and performing a t-test (Magurran and McGill, 2011; McDonald and Dimmick, 2003). Data collection, screening and analysis strategy are explained in the following sections.

\subsection{Step 1: Identifying and characterizing the intellectual core}

Social Media is an open field which is based on numerous and relevant exchanges with other disciplines such as organizational behaviour, innovation, and marketing. Consequently, selecting the most relevant journals becomes challenging. Various authors have commented on the difficulty of selecting the most relevant journals in whatever field of study (DuBois and Reeb, 2000; Lu, 2003). To avoid subjectivity in journal selection, we first identified the academic journals considered to be the most relevant to address the topic under study by making reference to the ABS Academic Journal Quality Guide v.4 categories ${ }^{1}$ (Harvey et al., 2010): General Management, Information Management, Innovation, Marketing, Organization Studies, Social Science, Strategic Management. The ABS Journal Quality Guide (v.4) provides wide journal coverage; has high levels of internal and external reliability; is sensitive to small variations in the ratings of journals, and is generally accepted as a fair means of ranking journals within its user community (Morris et al., 2009).

Within the described domain, we adopted and adapted a screening routine (Appio et al., 2014; David and Han, 2004) in order to identify the core articles. Since several terms may potentially refer to Social Media-based innovation, we used a number of words or phrases as well as Boolean combinations

\footnotetext{
${ }^{1}$ Within the ABS Journal Quality Guide v.4, we searched for top journals with a Quality Rating of 3, 4, and 4* publishing original and well-executed research papers. We filtered out journals with a Quality Rating below 3.
} 
of these in searching titles and keywords ${ }^{2}$. Data were extracted from the Science Citation Index Expanded (SCIEXPANDED); Social Sciences Citation Index (SSCI); Arts and Humanities Citation Index (A\&HCI) database of the Web of Science (WoS). The review was performed on articles published between 2003 and 2013. By reading abstracts and conclusions, relevance and consistency checks were performed; we also excluded papers that had both 'innovation' and 'Social Media' among keywords but did not really use Social Media to pursue innovation. As a consequence, from a total of 221 articles, 155 were selected as constituting the intellectual core. In Table 1, information concerning the number of journals and the number of articles, both before and after the screening routine, are reported in the timespan of reference.

Table 1. No. of journals and articles before (b_s) and after (a_s) the screening routine

\begin{tabular}{cc|cc|c}
\hline \multicolumn{2}{c|}{ \#Journals } & \multicolumn{2}{c|}{ \#Articles } & Timespan \\
\hline b_s & a_s & b_s & a_s & \\
\hline 92 & 59 & 221 & 155 & $2003-2013$ \\
\hline
\end{tabular}

We then mapped these 155 articles $^{3}$ against the journals in which they were published (Table 2): data followed Bradford's law ${ }^{4}$.

Table 2. No. of core articles per journal

\begin{tabular}{clrr}
\hline \#Articles & Journals & $\mathbf{\%}$ & $\mathbf{C u m . ~ \%}$ \\
\hline 10 & CREATIVITY AND INNOVATION MANAGEMENT & $6 \%$ & $6 \%$ \\
9 & INNOVATION-MANAGEMENT POLICY \& PRACTICE & $6 \%$ & $12 \%$ \\
8 & R\&D MANAGEMENT & $5 \%$ & $17 \%$ \\
8 & JOURNAL OF PRODUCT INNOVATION MANAGEMENT & $5 \%$ & $23 \%$ \\
8 & ORGANIZATION SCIENCE & $5 \%$ & $28 \%$ \\
8 & TECHNOVATION & $5 \%$ & $33 \%$ \\
7 & LONG RANGE PLANNING & $5 \%$ & $37 \%$ \\
7 & MIT SLOAN MANAGEMENT REVIEW & $5 \%$ & $42 \%$ \\
6 & INTERNATIONAL JOURNAL OF TECHNOLOGY MANAGEMENT & $4 \%$ & $46 \%$ \\
5 & HARVARD BUSINESS REVIEW & $3 \%$ & $49 \%$ \\
4 & MIS QUARTERLY & $3 \%$ & $52 \%$ \\
4 & RESEARCH POLICY & $3 \%$ & $54 \%$ \\
3 & CALIFORNIA MANAGEMENT REVIEW & $2 \%$ & $56 \%$ \\
3 & INDUSTRY AND INNOVATION & $2 \%$ & $58 \%$ \\
\hline
\end{tabular}

\footnotetext{
${ }^{2}$ Topic $=((($ social media" OR "social media-based" OR "social platform" OR ( "social network" AND (Facebook OR Twitter OR Flickr OR Linkedin)) OR "Facebook" OR "Twitter" OR "Flickr" OR "Linkedin" OR "Web-based platform*" OR "Web 2.0" OR "social software" OR "toolkit*" OR "open innovation software" OR "open innovation platform" OR "semantic web" OR "R\&D platforms" OR "design platform*" OR "idea* platform*" OR "online communit*" OR "brand communit*" OR "user communit*" OR "virtual customer" OR "virtual worlds" OR "virtual environment" OR "virtual integration" OR "crowdsourcing" OR "digital consumer" OR "virtual team") AND (innovation OR "idea generation" OR "product development" OR "ideation" OR "idea evaluation" OR "idea execution" OR "customer participation" OR "co-creation"))). Refined by: Web of Science Categories=( MANAGEMENT OR BUSINESS $)$ AND Document Types=( ARTICLE OR REVIEW ). Timespan=2003-2013. Databases=SCI-EXPANDED, SSCI, A\&HCI, CCR-EXPANDED, IC.

${ }^{3}$ The complete list of 155 core publications is provided as Supplementary Material.

${ }^{4}$ This law proposes that a few journals, publications, scientists, etc. contain the majority of articles, citations (Garfield, 1980).
} 


\begin{tabular}{|c|c|c|c|}
\hline 3 & INTERNATIONAL JOURNAL OF ELECTRONIC COMMERCE & $2 \%$ & $60 \%$ \\
\hline 3 & JOURNAL OF INTERACTIVE MARKETING & $2 \%$ & $62 \%$ \\
\hline 3 & MARKETING THEORY & $2 \%$ & $64 \%$ \\
\hline 3 & RESEARCH-TECHNOLOGY MANAGEMENT & $2 \%$ & $66 \%$ \\
\hline 3 & TECHNOLOGY ANALYSIS \& STRATEGIC MANAGEMENT & $2 \%$ & $68 \%$ \\
\hline 2 & INDUSTRIAL AND MARKETING MANAGEMENT & $1 \%$ & $69 \%$ \\
\hline 2 & INFORMATION SYSTEMS RESEARCH & $1 \%$ & $70 \%$ \\
\hline 2 & JOURNAL OF MACROMARKETING & $1 \%$ & $72 \%$ \\
\hline 2 & JOURNAL OF KNOWLEDGE MANAGEMENT & $1 \%$ & $73 \%$ \\
\hline 2 & JOURNAL OF BUSINESS RESEARCH & $1 \%$ & $74 \%$ \\
\hline 2 & JOURNAL OF MANAGEMENT AND INFORMATION SYSTEMS & $1 \%$ & $75 \%$ \\
\hline 2 & JOURNAL OF MARKETING & $1 \%$ & $77 \%$ \\
\hline 2 & MANAGEMENT SCIENCE & $1 \%$ & $78 \%$ \\
\hline 2 & MIS QUARTERLY EXECUTIVE & $1 \%$ & $79 \%$ \\
\hline 2 & ORGANIZATION STUDIES & $1 \%$ & $81 \%$ \\
\hline 1 & ACADEMY OF MANAGEMENT REVIEW & $1 \%$ & $81 \%$ \\
\hline 1 & ACADEMY OF MANAGEMENT PERSPECTIVES & $1 \%$ & $82 \%$ \\
\hline 1 & AFRICAN JOURNAL OF BUSINESS MANAGEMENT & $1 \%$ & $83 \%$ \\
\hline 1 & BUSINESS HORIZONS & $1 \%$ & $83 \%$ \\
\hline 1 & COMPUTERS AND HUMAN BEHAVIOR & $1 \%$ & $84 \%$ \\
\hline 1 & DECISION SUPPORT SYSTEMS & $1 \%$ & $85 \%$ \\
\hline 1 & ELECTRONIC COMMERCE RESEARCH AND APPLICATIONS & $1 \%$ & $85 \%$ \\
\hline 1 & ELECTRONIC MARKETS & $1 \%$ & $86 \%$ \\
\hline 1 & EUROPEAN JOURNAL OF MARKETING & $1 \%$ & $86 \%$ \\
\hline 1 & INFORMATION SYSTEMS AND E-BUSINESS MANAGEMENT & $1 \%$ & $87 \%$ \\
\hline 1 & INFORMATION AND ORGANIZATION & $1 \%$ & $88 \%$ \\
\hline 1 & INTERNATIONAL ENTREPRENEURSHIP AND MANAGEMENT JOURNAL & $1 \%$ & $88 \%$ \\
\hline 1 & INTERNATIONAL JOURNAL OF MARKET RESEARCH & $1 \%$ & $89 \%$ \\
\hline 1 & INTERNATIONAL JOURNAL OF CONTEMPORARY HOSPITALITY MANAGEMENT & $1 \%$ & $90 \%$ \\
\hline 1 & INTERNET RESEARCH & $1 \%$ & $90 \%$ \\
\hline 1 & JOURNAL OF MANAGEMENT AND INFORMATION SYSTEMS & $1 \%$ & $91 \%$ \\
\hline 1 & JOURNAL OF INTERACTIVE MARKETING & $1 \%$ & $92 \%$ \\
\hline 1 & JOURNAL OF PUBLIC POLICY \& MARKETING & $1 \%$ & $92 \%$ \\
\hline 1 & JOURNAL OR ORGANIZATIONAL BEHAVIOR & $1 \%$ & $93 \%$ \\
\hline 1 & JOURNAL OF MARKETING & $1 \%$ & $94 \%$ \\
\hline 1 & JOURNAL OF BUSINESS MARKETING & $1 \%$ & $94 \%$ \\
\hline 1 & JOURNAL OF SUPPLY CHAIN MANAGEMENT & $1 \%$ & $95 \%$ \\
\hline 1 & JOURNAL OF COMPUTER-MEDIATED COMMUNICATION & $1 \%$ & $95 \%$ \\
\hline 1 & JOURNAL OF SERVICE MANAGEMENT & $1 \%$ & $96 \%$ \\
\hline 1 & MANAGEMENT DECISION & $1 \%$ & $97 \%$ \\
\hline 1 & ORGANIZATIONAL DYNAMICS & $1 \%$ & $97 \%$ \\
\hline 1 & SCIENCE AND PUBLIC POLICY & $1 \%$ & $98 \%$ \\
\hline 1 & STRATEGIC ENTREPRENEURSHIP JOURNAL & $1 \%$ & $99 \%$ \\
\hline 1 & TECHNOLOGICAL FORECASTING AND SOCIAL CHANGE & $1 \%$ & $99 \%$ \\
\hline
\end{tabular}




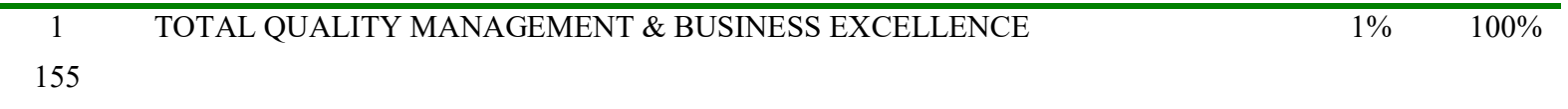

As one can notice, the distribution is highly skewed highlighting that only 12 journals $(\sim 20 \%)$ contain $84(\sim 54 \%)$ of the 155 selected articles. It also emerges that Creativity and Innovation Management, Innovation Management Policy \& Practice, and $R \& D$ Management are the key players in publishing Social Media related articles. However, there is a very long tail which contains the most cited articles in the sample (see APPENDIX 1): the most cited articles are 27 out of $155(\sim 17 \%)$. Comparing the numbers in Table 1 and APPENDIX 1, an interesting preliminary conclusion can be derived: some of the relevant papers in APPENDIX 1 belong to journals which show up in the long tail of the distribution of Table 1. Almost all the 17 journals publishing the highest number of articles are in APPENDIX 1 (except for Creativity and Innovation Management, International Journal of Technology Management and Harvard Business Review), with only Organization Science having 50\% of its articles contributing to the intellectual core. So, the 'long tail' emerging from Table 1 contributes relatively few publications to the topic, yet matters in term of relevance to the purpose of the intellectual core.

When it comes to considering the distribution of the articles over time (Figure 1), the Social Media literature tends to show a plateau at the beginning (2003-2008) with a peak in 2007; after 2008, the number of publications starts to increase at an average pace of 6 publications per year till 2012. The last two years do not show the same trend; rather, a plateau seems to occur echoing the same dynamics of the early years.

Figure 1. No. of core articles per year

In terms of topics, the following IPO framework is identified by reading keywords, abstracts and conclusions of the 155 core contributions:

- Input (preconditions influencing the process of Social Media-based Innovation)

○ Users' motivations and antecedents

- Firms' motivations and antecedents

- Process (occurring while Social Media-based Innovation activities develop)

○ Users' behaviors

- Social Platform characteristics and aims

○ Firms' behaviors

- Output (product of the process)

- Platform performance

- Firm performance and/or changes

Transversal to the IPO elements, a number of contingency factors are present. We refer to those internal (e.g., size of organization, goals) and external (e.g., customers, competitors) variables moderating or mediating the effects of Social Media-based Innovation.

\subsection{Step 2: Identifying and characterizing the originating research streams}

This study proposes the use of a mixed two-steps procedure: first, an objective selection of the main contributions and a bibliometric approach called Document Co-citation Analysis (DCA) applied on their references aiming at identifying the main clusters; second, a subjective screening of the identified clusters in order to reduce them in number, aggregating them around some key research streams. Relying on a subjective procedure applied to an objective selection of articles and clusters may mitigate the 
risks of starting subjectively and then applying some objective procedures (clustering/text-mining) on the resulting corpus.

Bibliometrics refers to "the collection, the handling, and the analysis of quantitative bibliographic data, derived from scientific publications" (Veerbek et al., 2002). One of the most common bibliometric techniques is co-citation analysis, a method used to examine relationships among articles or authors contributing to the development of a research field (Di Stefano et al., 2010; Vogel, 2012; Appio et al., 2014). Specifically, DCA studies a network of co-cited references (Small, 2003). The fundamental assumption is that co-citation clusters reveal the underlying intellectual structures; as such, the study of a co-citation network focuses on interpreting the nature of a cluster of cited documents and interrelationships between clusters (Chen et al., 2010).

With this methodology, our study aims at identifying the structure of the most important contributions to the field of Social Media. This structure shows the organization of the different research streams and whether or not these are linked together. This kind of analysis provides a useful tool for the study of possible 'research holes' and the orientation of future research lines. Finally, this article also aims at being a quick reference that allows new researchers to become familiar with this field of inquiry (Acedo and Casillas, 2005).

All DCA can do is identify influential authors/documents and display their interrelationships from the citation record. The strength of each document pair changes according to how many times it is cited in the literature selected. However, it is no substitute for extensive reading and fine-grained content analysis (White and McCain, 1998). Rather, it is complementary. The mixed two-step approach allows us to highlight both those items that underlie the deepest roots (in space and time) and those less deep but acting differently and having different purposes. Differently from purely subjective literature reviews, our approach let one notice the presence of well-established research streams, but also those whose debate is more horizontally distributed among different actors who struggle to assert their own reasons. Most importantly, DCA can be complemented by diversity analyses, which might provide the basis for further characterizing clusters in terms of knowledge base. This diversity (both within and between clusters) and its significance might further prove a sound basis for considering them as different originating Social Media streams.

In this study, we use VOSviewer version 1.6.1 (Van Eck and Waltman, 2010) to create, visualize, and explore bibliometric landscapes of science. Four parameters will help us in defining the final clusters configuration:

- clustering resolution, a non-negative value determining the specific level of detail we want to get from the set of our co-cited references (Waltman et al., 2010);

- normalization method (Van Eck and Waltman, 2009);

- minimum cluster size, identifying the minimum number of items within each cluster at the same time entailing a relatively large sample of words allowing for the analyses in Step 3;

- maximum number of iterations namely, the maximum number of iterations performed by the optimization algorithm of the VOS mapping technique.

\subsection{Step 3: Assessing the qualitative diversity of the originating research streams}

A qualitative assessment of the identified clusters was performed. This was done through a content analysis by using the text-mining routine in VOSviewer 1.6.1 (Van Eck and Waltman, 2011) considering Titles and Abstracts of the selected contributions. A term map is a two-dimensional map in which terms are located in such a way that the distance between two terms can be interpreted as an indication of the relatedness of the terms. In general, the smaller the distance between two terms, the stronger the terms are related to each other. The relatedness of terms is determined based on co-occurrences in documents. To create a term map based on a corpus of documents, VOSviewer distinguishes several steps: 
- Identification of noun phrases (Van Eck et al., 2010): this is done by performing a part-ofspeech tagging with The Apache OpenNLP toolkit. A filter is used to identify noun phrases. Finally, it converts plural noun phrases into singular ones.

- Selection of the most relevant noun phrases: for each noun phrase, the distribution of cooccurrences over all noun phrases is determined. This distribution is compared with the overall distribution of co-occurrences over noun phrases. The larger the difference between the two distributions (measured using the Kullback-Leibler distance), the higher the relevance of a noun phrase. Hence, it is assumed that in a co-occurrence network noun phrases with a high relevance are grouped together into clusters. Each cluster may be seen as a topic.

- Mapping and clustering of terms (Van Eck et al., 2010; Waltman et al., 2010; Waltman and Van Eck, 2013): this is done using the unified framework.

- Visualization of the mapping and clustering results: LinLog/modularity normalization was performed (Newman, 2004; Noack, 2007, 2009).

For each cluster, the full counting method was used and three was selected as a minimum number of occurrences of a term.

\subsection{Step 4: Assessing the quantitative diversity of the originating research streams}

Once the clusters were qualitatively described by using the text-mining routine in VOSviewer, a measure of intra- and inter-cluster diversity needs to be provided. This analysis was performed on the papers constituting the clusters, with the aim of better understanding how much and to what extent the knowledge base characterizing each cluster is diverse. In order to conclude whether a certain cluster is more diverse than another one, a t-test is used to test for differences in their diversity (Magurran and McGill, 2011). In the early 1960s, the concept of diversity was approached by measuring the information content of a long string of symbols, in the wake of some information theorists studies (Pielou, 1975). The basic idea of the analogy is to view an ecological sample of species as a 'message' with individual organisms as pieces of 'information' (Maurer and McGill, 2011). In this paper, the ecological species would refer to the references belonging to the five clusters; whilst, the number of individual organisms would indicate their relative abundance. A general measure of information content for an infinitely large set of symbols is called Renyi entropy of order $\alpha$. The value of interest for this study is the limit of the equation (Hill, 1973; Pielou, 1975) when $\alpha$ approaches 1, which yields:

$$
\mathrm{H}^{\prime}=\mathrm{R}_{\mathrm{i}}=-\sum_{i} p_{i} \log p_{i}
$$

where $p_{i}$ is the proportion of individuals found in the $i$-th species. This is the well-known ShannonWiener measure of species diversity ${ }^{5}$, which is widely used in a number of different areas (Stirling, 1998; McDonald and Dimmick, 2003). The Shannon-Wiener diversity index is used to assess dualconcept diversity as the quantification of diversity reflects both the number of classes and the degree of evenness of the apportionment (Junge, 1994). Keeping this definition in mind, we used the following measures to assess intra- and inter-cluster diversity:

- Shannon-Wiener diversity index $H^{\prime}$ (see equation 1): the value of this index is usually found to fall between 1.5 and 3.5 and only rarely surpasses 4.5 (Margalef, 1972);

- Evenness E: the maximum diversity $\left(\mathrm{H}_{\max }\right)$ which could possibly occur would be found in a situation where all species are equally abundant, in other words if $\mathrm{H}^{\prime}=\mathrm{H}_{\max }=\ln \mathrm{S}$ (where $\mathrm{S}$

\footnotetext{
${ }^{5}$ For a comprehensive mathematical justification of the index derivation and characterization, refer to Pielou (1969), Hutcheson (1970), Bowman et al. (1971).
} 
represents the species richness and indicates the total number of species identified in the sample). The ratio of observed diversity to maximum diversity can therefore be taken as a measure of evenness (E) (Pielou 1969). E is constrained between 0 and 1.0 with 1.0 representing a situation in which all species are equally abundant.

- Richness $S$ : the total number of species identified in the sample. It is among the simplest descriptors of community structure.

To calculate these three indices, we first collected all the papers within each cluster ${ }^{6}$, matched their names, and calculated their relative abundance.

\section{Results}

\subsection{Document Co-citation Analysis}

In order to understand which knowledge bases the intellectual core (155 articles) build upon, we performed a DCA on a corpus of 6,258 references ${ }^{7}$. Concerning the four parameters, we chose the lowest value allowed for the clustering resolution $(=1)$; the selected normalization method was based on normalizing the adjacency matrix of the network by using the association strength measure (Van Eck and Waltman, 2009); the minimum cluster size was set to 5; finally, the maximum number of iterations was set to 1,000. From the implementation of the VOSviewer technique, the following co-citation network can be extracted (see Figure 2):

Figure 2. Co-citation network of the Social Media references

Each dot on the map represents an article cited by at least one core article. The dimension of each dot denotes how many times a certain article appears in the references' dataset. Resulting co-citations range from 1 to 45 . We only show those from whom 20 links depart (see APPENDIX 2 for a list). Franke and Shah (2003) is the paper that can be considered the one from which 45 links depart. However, this does not mean that all co-citations departing from this paper are relevant. To gain insights on the importance of the co-citation link, we calculate the normalized co-citation weight (see APPENDIX 3 for a list). Indeed, it is shown that although Franke and Shah (2003), for example, is the one of the most cited articles, it does not show up in any of the most important co-cited links. We may conclude that if, on the one hand, Franke and Shah (2003) is an important document, on the other hand, it does not tend to build up important intellectual bridges.

VOSviewer identified 12 clusters. Further insights can be gained by visualizing the density of clusters based on the papers' proximity analysis. It allows us to identify a very limited set of papers, which are both at the center of very dense co-citation networks and the strongest connectors among clusters. It can also show how clusters evolved over time. To this purpose, three progressive time windows were considered: 2003-2006, 2007-2010 (which includes the first one) and 2011-2013 (which includes the first and second ones). Thusly, we were able to produce the density maps of the co-cited references of the intellectual core (Figures 3-5):

Figure 3. Co-cited references in the 2003-2006 time window

Figure 4. Co-cited references in the 2003-2010 time window

\footnotetext{
${ }^{6}$ Complete tables are available on request.

${ }^{7}$ The minimum number of citations of a cited reference is two. Out of 6,258 cited references, 1,019 meet the threshold.
} 
Figure 5. Co-cited references in the 2003-2013 time window

Red stains represent areas of greatest activity; font size relates to a certain paper's frequency of occurrence; and the position of papers in relation to each other represents the degree of relatedness of terms they have. Consequently, these figures offer insights into both the frequency of terms and their association to substantial research activity, as well as the relationship different important items have to one another. The item density of a point in a map depends both on the number of neighbouring items and on the weights of these items: the larger the number of neighbouring items and the smaller the distances between these items and the point of interest, the higher the item density. Also, the higher the weights of the neighbouring items, the higher the item density. Paper densities are then translated into colours using a colour scheme. Red corresponds to the highest paper density and blue corresponds to the lowest paper density. Basically, colours indicate the amount of attention researchers pay to some specific references located in the various areas of a concept map (Van Eck and Waltman, 2010).

The temporal evolution of the co-cited references shows that early contributions on Social Media (2003-2006) rely upon four distinct active areas revolving around some few key contributions, namely Jeppesen and Molin (2003), Von Hippel (2001), Thomke and Von Hippel (2002) for the biggest area; Brown and Eisenhardt (1995) and Burke et al. (2001) for the less active - but still recognized - area; Alavi and Leidner (2001) for the active to the right; Davis (1987) and Agrawal et al. (2001) for the upper area. As interest around this topic started growing, the four distinct areas of interest coalesced in a single large active area where important publications increased, as did key players in the field. Some authors remained leaders in this field (e.g., Von Hippel, Franke, Jeppesen) and further consolidated their attractiveness by publishing other interesting contributions; indeed, by looking at Figure 4, the contribution having the highest number of co-citation links are Franke and Shah (2003) (45 co-cit. links), Von Hippel (2005) (35 co-cit. links), Jeppesen and Frederiksen (2006) (34 co-cit. links), Von Hippel (2002) (31 co-cit. links). However, other authors (e.g., Chesbrough, Shah, Ebner, Muniz) entered the field later on, providing contributions which broadened the semantic characterization of the topic. These preliminary bibliometric analyses show that not only did some authors identify the intellectual core of the topic under study, but they were also often co-cited, becoming a reference point for future contributions which will shape the research field.

\subsection{Qualitative assessment}

After an accurate screening of the constituting articles, the 12 clusters were reduced to five by searching for similarities in terms of content (see APPENDIX 4-8 for a list) and implementing the textmining routine of VOSviewer. The relevance and occurrence of key terms were worked out. Labels and a short description follow.

\section{Cluster 1: Organizational Learning}

Cluster 1 was clearly identified and its density view is shown in Figure 6:

Figure 6. Relevance and occurrence of important terms in Cluster 1 
This group includes 169 papers in a time window 1934-2011. Most papers deal with the topic of organizational learning i.e. on how organizations create, retain, share and transfer knowledge, at different units of learning (individual, group, organizational and inter-organizational). It mainly contains papers based on social, collective, practice-related and community-centred understandings of knowledge creation and learning. Knowledge is held by individuals, but it is considered as embedded in the organizing principles through which individuals cooperate and learn within a social community. Such a community could be a group, an organization or a network (e.g., Sawhney and Prandelli, 2000; Wasko and Faraj, 2005). A strong focus is devoted to practices, at a micro level of investigation (e.g. Brown and Duguid, 1991). Qualitative research prevails, as testified by the many occurrences of Yin's paper (2003) about case study research design, Miles and Huberman's book (1994) about qualitative data analysis and Eisenhardt and Graebner's (2007) contribution about theory building from cases. Many papers date back to the 1990s. The seminal work of March (1991), which considers the relation between the exploration of new possibilities and the exploitation of old certainties in organizational learning, is also among the references having a higher weight.

\section{Cluster 2: Open and Distributed Innovation}

Cluster 2 is the result of the unification of original Clusters 2 and 6. Its density view follows in Figure 7:

Figure 7. Relevance and occurrence of important terms in Cluster 2

This group includes 239 papers in a time window 1955-2012. The thematic orientation of this cluster of references is best captured by the label 'Open and Distributed Innovation' as most publications included address the emergence of the new research stream for innovation from a managerial and organizational perspective. It includes the theoretical foundations of open and distributed innovation. Chesbrough (2003), von Hippel (2005), von Hippel and Katz (2002), Nambisan (2002), Dahan (2002) are the most cited contributions, as well as the Howe (2008) book on Crowdsourcing, a term that he coined in a June 2006 Wired article. Among the theoretical foundations, the cluster also includes Raymond (1999) that describes the "bazaar" of software developing and debugging based on an open peer to peer network, i.e. the Linux community. The paper uses the Linux experience to discuss the power of open and collaborative innovation processes with respect to the building of "cathedrals", carefully crafted by individuals or small isolated teams. More recent publications in the cluster deal with application open and distributed innovation principles in different contexts and present several case studies. Some of these are now considered research paradigmatic of open innovation (see e.g., Fuller, 2010; Ebner, 2009; Ogawa and Piller, 2006; Huston and Sakkab, 2006, Kohler et al., 2009). Cluster 2 also includes recent theoretical contributions on the conceptualization and value of open and distributed innovation (see e.g., Jeppesen and Lakhani, 2010; Dahlander and Gann, 2010) and on the different modes of collaboration involving different strategic trade-offs (Pisano and Verganti, 2009).

\section{Cluster 3: Value (Co)creation}

Cluster 3 originated from the convergence of Clusters 3, 4 and 9; its density is represented in Figure 8:

Figure 8. Relevance and occurrence of important terms in Cluster 3 
This group includes 293 papers in a time window 1958-2011. This group mainly includes literature dealing with the concept of value creation (especially in its further extension, i.e. value co-creation) at the interface of the firm and the customer. Although Vargo and Lusch (2004) - which introduces a revised logic for marketing focused on intangible resources, value creation, and relationships - is among the references with a higher weight in the cluster, most of the papers broaden horizons further. In value creation, value is created in the firm and then exchanged with the customer, whereas, in value cocreation, value is co-created by the firm in collaboration with the customer. Many papers refer to the concept of community and its recent development of web community (e.g., Sawhney et al., 2005; Fuller et al., 2006; Fuller et al., 2008), which is no longer restricted by geography. The focus is on the social mechanisms, practices, motivations and peculiarities of value co-creation by means of customers' collaboration. Attention is also payed to toolkits, which may support value co-creation (e.g., Franke and Piller, 2004). The cluster is characterized by a high relevance of qualitative research, particularly netnography, as testified by one of the references having a higher weight (Kozinets, 2002). Indeed, it is considered the paper that introduced this technique to study web communities. Many papers date from 2000. In many papers value co-creation is equated with co-innovation (e.g., Fuller et al., 2006; Fuller et al., 2008).

\section{Cluster 4: User/customer involvement in innovation processes}

Cluster 4 is the result of the unification of original Clusters 5 and 11. Its density view follows in Figure 9:

Figure 9. Relevance and occurrence of important terms in Cluster 4

This group includes 157 papers in a time window 1945-2010. The thematic orientation of this cluster of references is best captured by the label "User/customer involvement in innovation processes", as most publications in this cluster address the concept of user and his/her role in the innovation process. Many papers focus on the role of lead users i.e. on individuals or organizations who experience needs for a given innovation earlier than the majority of the target market (von Hippel, 1986). Some papers investigate the role of lead users in developing new industrial products (e.g., Urban and Von Hippel, 1988), others focus on the role of lead users in developing new consumer products (Morrison et al., 2000). Some papers focus on high-tech sectors (e.g., Lilien et al., 2002) while others on low-tech sectors (e.g., Herstatt and Von Hippel, 1991). Some papers focus on the concept of lead user itself (e.g., von Hippel, 1986), others on the so-called lead user method i.e. on the market research method built around the idea that just a few lead users hold the richest understanding of new product and service needs (Lilien et al., 2002). It is not surprising that many papers in the cluster are authored or coauthored by Eric von Hippel, who originally developed the term lead user in a seminal paper (von Hippel, 1986), which is also included. Further publications investigate the economics of products developed by users, the impact of sticky local information (von Hippel, 1994; von Hippel, 1998), the impact of lead user involvement at different stages of the innovation process (e.g., Gruner and Homburg, 2000) and the idea of outsourcing innovation tasks to users after equipping them with innovation toolkits (von Hippel, 2001; Franke and von Hippel, 2003; Thomke and von Hippel, 2003). Despite papers on lead users represent the majority inside the cluster, a few papers focus on other user types such as ordinary users (e.g., Balachandra, 1997; Novak et al., 2000).

\section{Cluster 5: Knowledge Sharing in Communities}

Cluster 5 is the result of the unification of original Clusters 7, 10 and 12. Its density view follows in Figure 10:

Figure 10. Relevance and occurrence of important terms in Cluster 5 
This group includes 161 papers in a time window 1979-2013. The thematic orientation of this cluster of references is best captured by the label "Knowledge Sharing in Communities", as most publications in this cluster address the phenomenon knowledge sharing and collaboration in communities. Most of the papers investigate motivational processes to participate in shared innovation efforts on voluntary basis within communities. Several contributions refer to open source projects (see e.g., Hertel et al., 2003; Shah, 2006; Hars, 2002), but this is not the rule. Jeppesen and Frederiksen (2006) consider the case of a firm-hosted user community of computer-controlled music instruments and investigate the intrinsic motivations of users to invest time and resources to contribute to the community, e.g. through free-revealing of innovation. Corrocher (2002) investigates the factors associated with the intensity of use of Web 2.0 services- video sharing, social networking and social bookmarking - by looking at the users' characteristics and at the technological features. It relies upon a theoretical framework that combines the diffusion of innovation model with the technology acceptance model. Frequently these papers are deeply rooted in social cognitive theories, such as self-efficacy by Bandura (1977) or grouplevel determinants of virtual communities participation - group norms and social identity - (Bagozzi and Lee, 2002), that are also included in the cluster. Some papers investigate the new economic and innovation model within Web 2.0 communities (von Hippel and von Krogh, 2003; Lerner and Tirole, 2004).

\section{Bridges between clusters}

Among the 80 most co-cited pairs, we detected 7 bridges among different clusters. Cluster 5 and Cluster 4 are the most connected with 3 connections each, Cluster 1 follows with two connections, whilst Cluster 3 and Cluster 2 have only one connection. This comes as no surprise. In fact, Cluster 5 and Cluster 4 deal with quite broad topics that are central to the issue of Social Media-based innovation, as they constitute their basic components: Web 2.0 Communities and Users with their needs.

For instance, Cluster 5 includes two papers (Corrocher, 2011; Cooke and Buckley, 2008) that bridge with the same paper in Cluster 1 (Bjelland and Wood, 2008). Bjelland and Wood (2008) is focused on lessons learned by IBM corporation with the "Innovation Jam" experience, that is a global innovation forum of stakeholders. Thus, it is a paper rooted in organizational learning discipline (Cluster 1) but absolutely close to Web 2.0 Community issues (Cluster 5). Moreover, Cluster 5 is connected - by means of the same paper (Chiu et al., 2006) - to Cluster 4 (Prahalad and Hamel, 1990) and to Cluster 3 (Hsu et al., 2007). Chiu et al. (2006) investigate knowledge sharing in virtual communities integrating social capital and social cognitive theories. Thus, it is logically connected to both Cluster 4, for what concerns user needs/motivation to participate, and to Cluster 3 for what concerns the aspects of social capital and value co-creation.

Figure 11. Clusters (most co-cited) bridges

It is worth noticing that the papers that are frequently co-cited with papers of other clusters (the bridges) are quite general in nature and consequently are not so representative of their own cluster. This is not surprising, on the contrary it seems to be a distinctive characteristic of bridges.

\subsection{Quantitative assessment}

Once the five clusters were identified using the VOSviewer technique, a measure of intra- and intercluster diversity was provided. The Shannon-Wiener diversity index, evenness, and richness were calculated (see Table 3):

Table 3. Diversity, Evenness, and Richness per cluster

\begin{tabular}{l|cc}
\hline Cluster & $\begin{array}{c}\text { Shannon-Wiener Div. Ind.* } \\
\text { Evenness** } \\
{[\mathrm{E}]}\end{array}$ & $\begin{array}{c}\text { Richness } \\
{[\mathrm{S}]}\end{array}$ \\
\hline
\end{tabular}




\begin{tabular}{l|ccc}
\hline $\mathrm{CL}_{1}$ : Organizational Learning & 2.515 & 0.701 & 36 \\
$\mathrm{CL}_{2}$ : Open and Distributed Innovation & 4.447 & 1.000 & 79 \\
$\mathrm{CL}_{3}:$ Value (Co)creation & 3.848 & 0.859 & 88 \\
$\mathrm{CL}_{4}$ : User/customer involvement in innovation processes & 4.035 & 0.977 & 62 \\
$\mathrm{CL}_{5}:$ Knowledge Sharing in Communities & 3.181 & 0.801 & 53 \\
\hline
\end{tabular}

*Jack-knifed estimation (Magurran and McGill, 2011); $1 \leq \mathrm{H}^{\prime} \leq 4.5$ (May, 1975; Margalef, 1972)

$* * 0 \leq \mathrm{E} \leq 1$ (Pielou, 1969)

Table 3 shows that only the diversity value for Clusters 2, 3 and 4 fall beyond the threshold of 3.5, meaning that these two clusters rely on very highly diverse sources of information to formulate theories and interpretations. Cluster 1 shows a low diversity value, meaning that the underlying knowledge base is quite homogeneous. Concerning Evenness, all clusters show a moderate-to-high apportionment among categories, meaning that they all contribute to creating the meaning of the clusters. Cluster 2 contains the highest number of categories (79), whilst Cluster 1 the lowest (36).

In order to increase further the precision of the measurements, a jack-knifed estimate of the diversity indices was worked out. Jack-knifing is a technique which allows the estimate of virtually any statistic to be improved (Magurran and McGill, 2011). The method was applied to diversity statistics by Zahl (1977). Adams and McCune (1979) and Heltshe and Bitz (1979) have also investigated its effectiveness in this context. The method's advantage is that it makes no assumptions about the underlying distribution. Instead, a series of jack-knifed estimates and pseudo values are produced. These pseudo values are normally distributed and their mean forms the best estimate of the statistic (Magurran and McGill, 2011).

Next, we decided to assess whether the diversity among clusters was significant. Hutcheson's t-test ${ }^{8}$ allows the diversities of the five clusters to be compared (Magurran and McGill, 2011). The null hypothesis $\mathrm{H} 0$ states that "two Shannon diversity indices come from two communities with equal species diversity". Basically, not rejecting H0 would mean having two clusters sharing a homogenous knowledge base; rejecting H0, on the contrary, would mean proving that the two clusters under study represent two different communities or research streams. T-tables quickly revealed that all paired comparisons resulted in a highly significant difference in their inter-cluster diversity (Table 4):

Table 4. T-test to assess inter-cluster diversity

\begin{tabular}{|c|c|c|c|c|c|}
\hline & $\mathbf{H}_{1}^{\prime}, \mathrm{JK}$ & $\mathbf{H}_{2,}^{\prime}, \mathrm{JK}$ & $\mathbf{H}_{3, \mathrm{JK}}$ & $\mathrm{H}_{4, \mathrm{JK}}^{\prime}$ & $\mathrm{H}^{\prime}{ }_{5, \mathrm{JK}}$ \\
\hline $\mathbf{H}^{\prime}{ }_{1, \mathrm{JK}}$ & & & & & \\
\hline $\mathbf{H}_{2}^{\prime}, \mathrm{JK}$ & $* * *$ & & & & \\
\hline $\mathbf{H}_{3, \mathrm{JK}}$ & $* * *$ & $* * *$ & & & \\
\hline $\mathbf{H}_{4}^{\prime}$, JK & $* * *$ & $* * *$ & * & & \\
\hline $\mathbf{H}^{\prime}{ }_{5}, \mathrm{JK}$ & $* * *$ & $* * *$ & $* * *$ & $* * *$ & \\
\hline
\end{tabular}

\footnotetext{
${ }^{8}$ A note of caution: the Shannon-Wiener diversity index is a non-parametric index. Hence, no assumptions are made about the shape of the underlying species abundance distribution (Southwood and Henderson, 2000; Magurran and McGill, 2011). A substantial error can arise when the sample does not include all the species in the community (Peet, 1974); however, as the true species richness of an assemblage is usually unknown, an unbiased estimator of the Shannon-Wiener index does not exist (Lande, 1996). Hutcheson (1970), by assuming that each population is normally (or nearly normally) distributed and that the values of real variances are not known, advanced a test with a statistic following an approximate t-distribution with specific degrees of freedom. Deviations from these assumptions may invalidate t-test results; assessments concerning significant differences of cluster diversities may rely on absolute (jack-knifed) values of the Shannon-Wiener index only.
} 
We thus provided statistical evidence that the five Clusters are significantly different; indeed, the diversity of their knowledge base is a remarkable sign of cluster heterogeneity. Cluster 3 and 4 show a partial overlap in that their knowledge bases are not highly significantly different (see Table 4). Accordingly, we may argue that the five clusters could constitute five competing scientific research streams (Small, 2003). Although claiming this for a relatively young research field may be risky on the basis of our data, it is reasonable to argue that such dynamics are still undergoing. These results are confirmed even when outliers are dropped out from each cluster.

\section{Linking originating research streams and intellectual core}

Having identified and characterized through the IPO framework the 155 contributions delineating the intellectual core of the Social Media-based Innovation research field, and having described the five originating research streams, we then link them providing the reader with a comprehensive map of the development of the field (Figure 12).

Figure 11. Clusters contribution to the development of the field

The majority of the papers defining the first originating research stream (Cluster 1) flow into the Firms' motivations and antecedents (Input), Firms' behaviours (Process), and Firms' performance and/or changes (Output). It emerges that this originating research stream, grounded on the Organizational Learning, has transversal influence but mainly focuses on the Social Media-based innovation from the side of the firms. The second originating research stream (Cluster 2) has contributions which transversally impact the same pillars of the IPO framework of the Cluster 1, but it also contributes to define the Users' behaviour pillar (Process). This is consistent with the content of Cluster 2 in that the Open and Distributed Innovation research stream entails considerations on the innovation processes at both the individual and firm levels. The third originating research stream (Cluster 3 ) has the highest number of contributions and the largest impact on the IPO pillars namely, Users' and Firms' motivations and antecedents (Input), Social platforms' characteristics and aims Firm's behaviours (Process) and Platform performance (Output). This stream seem to shape the way we conceptualize the Value (Co)creation by mainly focusing on the Social Media platform in itself. The fourth originating research stream (Cluster 4) has at its core the user theory and creates the link between the Users' motivations and antecedents (Input) and the Social platforms' characteristics and aims (Process). Finally, the fifth originating research stream (Cluster 5) focuses on topics related to knowledge sharing in communities and its contributions shape the way we currently see described the link between Users' behaviour (Process) and the Platform performance (Output).

\section{Conclusions and implications}

In this article, we have provided a systematic analysis of the most influential contributions shaping the Social Media-based innovation research field. A decade of contributions was scrutinized by implementing a four-step routine.

We first identified the contributions constituting the intellectual core through a systematic routine: 155 contributions were selected; their main topics were characterized in terms of an IPO framework. Second, a mixed two-steps procedure was applied on the main references of the 155 core contributions: first, we applied a DCA to their knowledge bases (1,094 references) to unveil the most important cocited pairs and clusters; then, a qualitative assessment of clusters followed in order to reduce them in number (from 12 to 5) on the basis of results coming from a content analysis. Afterwards, the main bridges between clusters have been identified. Emerging results from these two steps complement and cross-validate existing qualitative reviews. Indeed, our systematic assessment provides quite a rich overview of the research streams shaping the first decade of Social Media-based innovation. A peculiar outlook on the heterogeneity of knowledge bases characterizing it is provided as well, whilst the VOSviewer text-mining routines were instrumental to unveil the relevance and occurrence of the most 
important terms. Then, we worked out a quantitative assessment of the five resulting clusters providing the reader with an objective measure of intra- and inter-cluster diversity, as well as testing for its significance. Finally, we linked the originating five research streams to the state of the art of the topic represented by the 155 core contributions. Interesting insights emerged.

First, based on a DCA, our analysis reveals that Social Media-based innovation is rooted in five coexisting research streams whose knowledge bases point towards five different knowledge areas: $O r$ ganizational Learning (Cluster 1), Open and Distributed Innovation (Cluster 2), Value (Co)creation (Cluster 3), User/customer involvement in innovation processes (Cluster 4), Knowledge Sharing in Communities (Cluster 5). In terms of richness (S), Social Media-based innovation is mainly influenced by studies in Open and Distributed Innovation along with Value (Co)creation. These two clusters, and the one labelled as User/customer involvement in innovation processes, have very highly diversified but evenly distributed - knowledge bases; on the contrary, the others show moderate diversity.

Second, but it comes as no surprise, the great majority of the knowledge bases characterizing this topic are quite general in nature; this reveals that Social Media-based Innovation is a relatively new field of investigation. Time is needed in order to see more focused research streams emerge.

Third, and as a consequence, these five research streams are shaping different pillars of the IPO framework. Some of them have a quite transversal impact: Clusters 1, 2, and 3 shape the content of the pillars related to the users' and firms' antecedents (Input), users'/firms' behaviours and platform characteristics (Process), and platform/firm's performance (Output); Clusters 4 and 5 are respectively more focused on the link between Input and Process, and Process and Output. It also becomes visible the partial overlapping between Cluster 3 and Cluster 4. All in all, although there is a good balance between the components of the IPO, the pillars that are more impacted by the five originating research streams are those belonging to the Process one. It may be because research concerning the users' behaviour, firms' behaviours, and social platforms' characteristics and aims are more complex as they need to be enacted by a complex combination of originating streams.

Fourth, almost all originating research streams contain papers dating back mainly to the 1930s-1950s time window: on average, it took more than 50 years for the Social Media-based innovation to emerge as the distinctive body of knowledge characterized by the 155 core contributions. And as Social Media-based innovations are seen to be quite promising in their impact we may argue, in line with Golder and co-authors (2009), that it is radical in nature both from a technological (Papagiannidis and Boulakis, 2015) and innovative (Ooms et al., 2015) standpoints. However, as the five research streams run in parallel, we may say that the Social Media-based innovation will probably undergo some fundamental changes and then its full impact has yet to concretize. After all, and consistently, some recent contributions are pointing towards reading the Social Media phenomenon and its link with innovation process through the complexity (and paradox) lenses (Jalonen, 2015).

Finally, some papers which are quite general in nature act as bridges among different clusters. They represent part of the background knowledge on which the Social Media-based innovation research field stands. Cluster 5 and Cluster 4 are the most connected with 3 connections each and this comes as no surprise as they basically deal with quite broad topics that are central to the issue of Social Mediabased innovation (i.e. Web 2.0 Communities and Users with their needs). The fact that few bridges are detected is due to the inherent diversity of clusters to which their extremes belong (correctly detected by our diversity indicators); this also signals that the signals of convergence of these research streams are weak but existing.

\section{Limitations and ideas for future research}

Some limitations need to be mentioned. The first one is that the paper's attention was focused only on the most influential academic journals in the field. The value of non-academic contributions (e.g., books, proceedings, working papers) should also be assessed in order to have a more comprehensive picture. A second limitation is that, when retrieving the sample, an attempt was made to include all commonly-known keywords related to Social Media phenomena; however, Social Media is a fast evolving phenomenon and some keywords may have not been included in our knowledge base. Fur- 
thermore, DCA is valid only as a partial analysis and presents only an archival view of a field. This is why its analyses should complement a literature review carried out with subjective approaches. Also, this study sets out a starting point for further analyses that aim at better understanding the Social Media-based innovation research field.

In turn, to refine the outcomes of this study, further research should be undertaken to identify how the different approaches (clusters) have evolved over time by means of objective procedures instead of solely expert opinions. This idea can be used to explain the evolution of the science and the competition of the research streams (Chen et al., 2002; Small, 2003; White, 2003). Finally, a wider range of document typologies (e.g. books, working papers, research notes, proceedings) should be considered in order to obtain a more detailed description of the Social Media-based innovation research field.

\section{References}

Adams, J. E. and McCune, E. D. (1979). Application of the generalized jack-knife to Shannon's measure of information used as an index of diversity. In Ecological Diversity in Theory and Practice (Eds. J. F. Grassle, G. P. Patil, W. Smith and C. Taille), International Co-operative Publishing House, Fairland, MD, pp. 117- 31.

Agrawal, M., Kumaresh, T.V., and Mercer, G.A. (2001). The false promise of mass customization. The McKinsey Quarterly, 3, 62-71.

Ajzen, I. (1988). Attitudes, personality and behavior. Milton Keynes: Open University Press.

Alavi, M., and Leidner, D.E. (2001). Review: Knowledge Management and Knowledge Management Systems: Conceptual foundations and research issues. MIS Quarterly, 25(1), 107-136.

Amabile, T. (1996). Creativity in context. Boulder, CO: Westview Press.

Appio, F., Cesaroni, F., and Di Minin, A. (2014). Visualizing the structure and bridges of the intellectual property management and strategy literature: a document co-citation analysis. Scientometrics, 101(1), 623-661.

Avital, M., and Te'eni, D. (2009). From generative fit to generative capacity: exploring an emerging dimension of information systems design and task performance. Information Systems Journal, 19(4), 345-367.

Bagozzi, R. (1992). The self-regulation of attitudes, intention, and behavior. Social Psychology Quarterly, 55(2), 178-204.

Balachandra, R., and Friar, J.H. (1997). Factors for success in R\&D projects and new product innovation: a contextual framework. IEEE Transactions on Engineering Management, 44(3), 276-287.

Bandura, A. (1977). Self-efficacy: toward a unifying theory of behavioral change. Psychological Review, 84(2), 191-215.

Bandura, A. (1997). Self-Efficacy: The Exercise of Control. New York: W.H. Freeman.

Barney, J. (1991). Firm resources and sustained competitive advantage. Journal of Management, 17(1), 99-120.

Battistella, C., and Nonino, F. (2012). Open innovation web-based platforms: The impact of different forms of motivation on collaboration. Innovation Management Policy and Practice, 14(4), 557575.

Bayus, B.L. (2013). Crowdsourcing New Product Ideas over Time: An Analysis of the Dell IdeaStorm Community. Management Science, 59(1), 226-244.

Bjelland, O.M., and Wood, R.C. (2008). An inside view of IBM's 'Innovation Jam'. MIT Sloan Management Review, 50(1), 32-40.

Bolton, R.N., Parasuraman, A., Hoefnagels, A., Migchels, N., Kabadayi, S., Gruber, T., Loureiro, Y.K., and Solnet, D. (2013). Understanding Generation Y and their use of social media: a review and research agenda. Journal of Service Management, 54(3), 245-267.

Bowman, K.O., Hutchenson, K., Odum, E.P., and Shenton, L.R. (1971). Comments on the distribution of indices of diversity. In Statistical Ecology, eds. G. P. Patil, E. C. Pielou and W. E. Waters, pp. 315-359. London: Pennsylvanian State University Press. 
Brown, J., and Duguid, P. (1991). Organizational learning and communities of practice: toward a unified view of working, learning, and innovating. Organization Science, 2(1), 40-57.

Brown, S.L., and Eisenhardt, K.M. (1995). Product development: past research, present findings, and future directions. Academy of Management Review, 20(2), 343-378.

Bucy, E.P., and Gregson, K.S. (2001). Media participation: A legitimizing mechanism of mass democracy. New Media \& Society, 3(3), 357-380.

Bullinger, A.C., Neyer, A.K., Rass, M. and Moeslein, K.M. (2010). Community-based innovation contests: Where competition meets cooperation. Creativity and Innovation Management, 19(3): 290303.

Burke, R.R., Rangaswamy, A., and Gupta, S. (2001). Rethinking market research in the digital world. In J. Wind, V. Mahajan Eds. Digital Marketing. Global Strategies from the World's Leading Experts, New York: John Wiley \& Sons, pp. 226-255.

Chen, C., Cribbin, T., Macredie, R., and Morar, S. (2002). Visualizing and tracking the growth of competing research streams: Two case studies. Journal of the American Society for Information Science and Technology, 53(8), 678-689.

Chen, C., Ibekwe-SanJuan, F., and Hou, J. (2010). The Structure and Dynamics of Co-Citation Clusters: A Multiple-Perspective Co-Citation Analysis. Journal of the American Society for Information Science and Technology, 61(7), 1386-1409.

Chesbrough, H. W. (2003). Open innovation: The new imperative for creating and profiting from technology. Harvard Business Press.

Chesbrough, H. W. (2011). Open services innovation. Rethinking your business to grow and compete in a new era. John Wiley \& Sons.

Chiu, C.-M., Hsu, M.-H., and Wang, E.T.G. (2006). Understanding knowledge sharing in virtual communities: an integration of social capital and social cognitive theories. Decision Support Systems, 42(3), 1872-1888.

Coase, R. (1937). The nature of the firm. Economica, 4(16), 386-405.

Cooke, M., and Buckley, N. (2008). Web 2.0 Social networks and the future of market research. International Journal of Market Research, 50(2), 267-292.

Corrocher, N. (2011). The adoption of Web 2.0 services: An empirical investigation. Technological Forecasting \& Social Change, 78(4), 547-558.

Cortizo, J. C., Carrero, F. M., and Gómez, J. M. (2011). Introduction to the special issue: mining Social Media. International Journal of Electronic Commerce, 15(3), 5-8.

Csikszentmihalyi, M. (1975). Play and intrinsic rewards. Journal of Humanistic Psychology, 15(3), 41-63.

Csikszentmihalyi, M. (1990). Flow: Psychology of Optimal Experience. New York: Harper \& Row.

Culnan, M. J., McHugh, P. J., and Zubillaga, J. I. (2010). How large US companies can use Twitter and other social media to gain business value. MIS Quarterly Executive, 9(4), 243-259.

Cusumano, M.A., and Nobeoka, K. (1991). Strategy, structure and performance in product development: observations from the auto industry. Research Policy, 21(3), 265-293.

Dahl, D.W., and Moreau, P.C. (2007). Thinking inside the box: why consumers enjoy constrained creative experience. Journal of Marketing Research, 44(3), 357-369.

Dahlander, L. and Frederiksen, L. (2012). The Core and Cosmopolitans: A Relational View of Innovation in User Communities. Organization Science, 23(4), 988-1007.

David, R.J., and Han, S.K. (2004). A systematic assessment of the empirical support for transaction cost economics. Strategic Management Journal, 25(1): 39-58.

Davis, S.M. (1987). Future perfect. Reading, MA: Addison-Wesley.

Di Gangi, P. M. and Wasko, M. (2009). Steal my idea! Organizational adoption of user innovations from a user innovation community: A case study of Dell IdeaStorm. Decision Support Systems, $48(1), 303-312$. 
Di Gangi, P. M., Wasko, M., and Hooker, R. (2010). Getting customers' ideas to work for you: Learning from Dell how to succeed with online user innovation communities. MIS Quarterly Executive, 9(4), 213-228.

Di Stefano, G., Peteraf, M., and Verona, G. (2010). Dynamic capabilities deconstructed: a bibliographic investigation into the origins, development, and future directions of the research domain. Industrial and Corporate Change, 19(4), 1187-1204.

Ebner, W., Leimeister, J. M. and Krcmar, H. (2009). Community engineering for innovations: the ideas competition as a method to nurture a virtual community for innovations. $R \& D$ Management, 39(4), 342-356.

Effing, R., and Spil, T.A.M. (2016). The social strategy cone: towards a framework for evaluating social media strategies. International Journal of Information Management, 36(1), 1-8.

Faraj, S. Jarvenpaa, S.L., and Majchrzak, A. (2011). Knowledge Collaboration in Online Communities. Organization Science, 22(5), 1224-1239.

Franke, N., and Shah, S. (2003). How communities support innovative activities: an exploration of assistance and sharing among end-users. Research Policy, 32(1), 155-178.

Franke, N. and Piller, F. T. (2003). Key research issues in user interaction with user toolkits in a mass customisation system. International Journal of Technology Management, 26(5), 578-599.

Füller, J. (2010). Refining Virtual Co-Creation from a Consumer Perspective. California Management Review, 52(2), 98-122.

Füller, J., and Matzler, K. (2007). Virtual product experience and customer participation-A chance for customer-centred, really new products. Technovation, 27(6), 378-387.

Füller, J., Faullant, R., and Matzler, K. (2010). Triggers for virtual customer integration in the development of medical equipment from a manufacturer and a user' s perspective. Industrial Marketing Management, 39(8), 1376-1383.

Füller, J., Hutter, K., and Faullant, R. (2011). Why co-creation experience matters? Creative experience and its impact on the quantity and quality of creative contributions. $R \& D$ Management, 41(3), 259-273.

Füller, J., Jawecki, G. and Muhlbacher, H. (2007). Innovation creation by online basketball communities. Journal of Business Research, 60(1), 60-71.

Füller, J., Lenz, A., and Pirker, C. (2010). Innovation Management 2.0: How to Organize Innovation in the Era of Social Media. Performance, 3(2), 28-35.

Füller, J., Matzler, K., and Hoppe, M. (2008). Brand community members as a source of innovation. Journal of Product Innovation Management, 25(6), 608-619.

Füller, J., Muhlbacher, H., Matzler, K., and Jawecki, G. (2009). Consumer empowerment through internet-based co-creation. Journal of Management Information Systems, 26(3), 71-102.

Gallagher, J., and Ranbotham, S. (2010). Social Media and Customer Dialog Management at Starbucks. MIS Quarterly Executive, 9(4), 197-212.

Gan, C., and Wang, W. (2015). Research characteristics and status on social media in China: a bibliometrics and co-word analysis. Scientometrics, 105(2), 1167-1182.

He, W., and Wang, F. K. (2015). A process-based framework of using social media to support innovation process. Information Technology and Management, 1-15.

Heltshe, J. F. and Bitz, D. W. (1979) Comparing diversity measures in sampled communities. In Ecological Diversity in Theory and Practice (Eds. F. Grassle, G. P. Patil, W. Smith and C. Taille), International Co-operative Publishing House, Fairland, MD, pp.133-44.

Hienerth, C., Keinz, P., and Lettl, C. (2011). Exploring the nature and implementation process of usercentric business models. Long Range Planning, 44(5), 344-374.

Hill, M.O. (1973). Diversity and evenness: a unifying notation and its consequences. Ecology, 54(2), 427-432.

Hsu, M.-H., Ju, T.L., Yen, C.-H., and Chang, C.-M. (2007). Knowledge sharing behavior in virtual communities: the relationship between trust, self-efficacy, and outcome expectations. International Journal of Human-Computer Studies, 65(2), 153-169. 
Hutcheson, K. (1970). A Test for Comparing Diversities based on the Shannon Formula. Journal of Theoretical Biology, 29(1), 151-4.

Hutter, K., Hautz, J., Füller, J., Mueller, J. and Matzler, K. (2011). Communitition: The tension between competition and collaboration in community-based design contests. Creativity and Innovation Management, 20(1), 3-21.

Golder, P. N., Shacham, R., and Mitra, D. (2009) Innovations' origins: When, by whom, and how are radical innovations developed?, Marketing Science, 28(1), 166-179.

Jalonen, H. (2015). Dancing with the paradox - social media in innovation through complexity lens. International Journal of Innovation Management, 19(1), 1-26.

Jarvenpaa, S.L., and Lang, K.R. (2011). Boundary Management in Online Communities: Case Studies of the Nine Inch Nails and ccMixter Music Remix Sites. Long Range Planning, 44(5-6), 440-457.

Jeppesen, L.B. (2005). User toolkits for innovation: Consumers support each other. Journal of Product Innovation Management, 22(4), 347-362.

Jeppesen, L.B., and Frederiksen, L. (2006). Why do users contribute to firm-hosted user communities? The case of computer-controlled music instruments. Organization Science, 17(1), 45-63.

Jeppesen, L.B., and Molin, M.J. (2003). Consumers as co-developers: Learning and innovation outside the firm. Technology Analysis and Strategic Management, 15(3), 363-383.

Junge, K. (1994). Diversity of ideas about diversity measurement. Scandinavian Journal of Psychology, 35(1), 16-26.

Kaplan, A.M., and Haenlein, M. (2010). Users of the world, unite! The challenges and opportunities of Social Media. Business Horizons, 53(1), 59-68.

Khan, G.F. (2013). Social media-based systems: an emerging area of information systems research and practice. Scientometrics, 95(1), 159-180.

Kogut, B., and Zander, U. (1992). Knowledge of the firm, combinative capabilities, and the replication of technology. Organization Science, 3(3), 383-397.

Kohler, T. Matzler, K., and Fuller, J. (2009). Avatar-based innovation: Using virtual worlds for realworld innovation. Technovation, 29(6-7), 395-407.

Kohler, T., Fuller, J., Matzler, K., and Stiegler, D. (2011). Co-creation in virtual worlds: the design of user experience. MIS Quarterly, 35(3), 773-788.

Kozinets, RV., Hemetsberger, A., and Schau, H.J. (2008). The Wisdom of Consumer Crowds Collective Innovation in the Age of Networked Marketing. Journal of Macromarketing, 28(4), 339-354.

Lande, R. (1996). Statistics and partitioning of species diversity, and similarity among multiple communities. Oikos, 76(1), 5-13.

Lazear, E.P., and Rosen, S. (1981). Rank-Order tournaments as optimum labor contracts. Journal of Political Economy, 89(5), 841-864.

Li, C., and Bernoff, J. (2008). Groundswell: winning in world transformed by social technologies. Boston, MA: Harvard Business Press.

Magurran, A.E., and McGill, B.J. (2011). Biological Diversity: frontiers in measurement and assessment. Oxford: Oxford University Press.

Margalef, R. (1972). Homage to Evelyn Hutchinson, or why there is an upper limit to diversity. Transactions of the Connecticut Academy of Arts and Sciences, 44, 211-235.

Martini A., Massa S., Testa S. 2013. The Firm, the Platform and the Customer: A 'Double Mangle' Interpretation of Social Media for Innovation. Information \& Organization, 23(3), 198-213

Martini A., Massa S., Testa S. 2014. Customer co-creation projects and social media: The case of Barilla of Italy, Business Horizon, 57, 425-434.

May, R. M. (1975). Patterns of species abundance and diversity. In Ecology and Evolution of Communities (eds. M. L Cody and J M. Diamond), Harvard University Press, Cambridge, MA, pp. 81-120.

McCain, K.W. (1990). Mapping authors in intellectual space: a technical overview. Journal of the American Society for Information Science, 41(6), 433-443.

McDonald, D.G., and Dimmick J. (2003). The Conceptualization and Measurement of Diversity. Communication Research, 30(1), 60-79. 
Nambisan, S. (2002). Designing virtual customer environments for new product development: toward a theory. Academy of Management Review, 27(3), 392-413.

Nambisan, S., and Baron, R.A. (2010). Different Roles, Different Strokes: Organizing Virtual Customer Environments to Promote Two Types of Customer Contributions. Organization Science, 21(2), 554-572.

Nambisan, S., and Nambisan, P. (2008). Innovation - How to profit from a better 'Virtual Customer Environment'. MIT Sloan Management Review, 49(3), 53.

Newman, M. E. J. (2004). Fast algorithm for detecting community structure in networks. Physical Review E, 69(6), 066133.

Ngai, E.W.T., Moon, K.-I.K., Lam, S.S., Chin, E.S.K., and Tao, S.S.C. (2015a). Social media models, technologies, and applications: an academic review and case study. Industrial Management \& Data Systems, 115(5), 769-802.

Ngai, E.W.T., Tao, S.S.C., and Moon, K.-I.K. (2015b). Social media research: theories, constructs, and conceptual frameworks. International Journal of Information Management, 35(1), 33-44.

Noack, A. (2007). Energy models for graph clustering. Journal of Graph Algorithms and Applications, $11(2), 453-480$.

Noack, A. (2009). Modularity clustering is force-directed layout. Physical Review E, 79(2), 026102.

Ooms W., Bell. J., and Kok R.A.W. (2015). Use of Social Media in Inbound Open Innovation: Building Capabilities for Absorptive Capacity. Creativity and Innovation Management, 24(1), 136-150.

Papagiannidis, S., and Bourlakis, M. (2015). Special Issue introduction - Social Media: A revolution in communication. Technological Forecasting and Social Change, 95, 1-2.

Peet, R.K. (1974). The measurement of species diversity. Annual Review of Ecology and Systematics, 5: 285-307.

Pielou, E.C. (1969). An introduction to mathematical ecology. New York: Wiley Interscience, John Wiley \& Sons.

Pielou, E.C. (1975). Species abundance distributions. In Ecological Diversity, pp. 19-31. New York: Wiley Interscience.

Piller, F.T., and Walcher, D. (2006). Toolkits for idea competitions: a novel method to integrate users in new product development. $R \& D$ Management, 36(3), 307-318.

Piller, F., Vossen, A., and Ihl, C. (2012). From Social Media to Social Product Development: The Impact of Social Media on Co-Creation of Innovation. Die Unternehmung, 65(1), 7-27.

Poetz, MK., and Schreier, M. (2012). The Value of Crowdsourcing: Can Users Really Compete with Professionals in Generating New Product Ideas? Journal of Product Innovation Management, 29(2), 245-256.

Prahalad, C.K., and Hamel, G. (1990). The core competence of the corporation. Harvard Business Review, 68(3), 79-91.

Prandelli, E., Verona, G., and Raccagni, D. (2006). Diffusion of Web-based product innovation. California Management Review, 48(4), 109-135.

Prugl, R., and Schreier, M. (2006). Learning from leading-edge customers at The Sims: opening up the innovation process using toolkits. $R \& D$ Management, 36(3), 237-250.

Santos, F.M., and Eisenhardt, K.M. (2009). Constructing markets and shaping boundaries: entrepreneurial power in nascent fields. Academy of Management Journal, 52(4), 643-671.

Schau, H.J., Muniz, A.M., and Arnould, E.J. (2009). How Brand Community Practices Create Value. Journal of Marketing, 73(5), 30-51.

Shirky, C. (2008). Here comes everybody: the power of organizing without organizations. London: Penguin Books.

Sidiropoulos, A., Katsaros, D., and Manolopoulos, Y. (2007). Generalized Hirsch h-index for disclosing latent facts in citation networks. Scientometrics, 72(2), 253-280.

Small, H. (2003). Research streams, citations, and maps of science: A personal history. Journal of the American Society for Information Science and Technology, 54(5), 394-399.

Sorensen, E. (1997). Democracy and empowerment. Public Administration, 75(3), 553-567. 
Southwood, T.R.E., and Henderson, P.A. (2000). Ecological Methods. Blackwell Science.

Stirling, A. (1998). On the Economics and Analysis of Diversity. SPRU Working Paper, no. 28.

Thomke, S., and Von Hippel, E. (2002). Customers as Innovators: A New Way to Create Value. Harvard Business Review, April, 74-81.

Van Eck, N. J., and Waltman, L. (2010). Software survey: VOSviewer, a computer program for bibliometric mapping. Scientometrics, 84(2), 523-538.

Van Eck, N. J., Waltman, L., Dekker, R., and Van den Berg, J. (2010). A comparison of two techniques for bibliometric mapping: Multidimensional scaling and VOS. Journal of the American Society for Information Science and Technology, 61(12), 2405-2416.

Van Eck, N.J., Waltman, L., Noyons, E.C.M., and Buter, R.K. (2010). Automatic term identification for bibliometric mapping. Scientometrics, 82(3), 581-596.

Van Eck, N. J., and Waltman, L. (2011). Text mining and visualization using VOSviewer. ISSI Newsletter, 7(3), 50-54.

Van Osch, W., and Avital, M. (2010). Generative Collectives. Proceedings of the $31^{\text {st }}$ International Conference on Information Systems Conference (ICIS), December, St Louis, MO.

Vogel, R. (2012). The Visible Colleges of Management and Organization Studies: A Bibliometric Analysis of Academic Journals. Organization Studies, 33(8), 1015-1043.

Von Hippel E. (1986). Lead users: a source of novel product concepts. Management Science, 32(7), 791-805.

Von Hippel E. (2002). Horizontal innovation networks by and for users. Working paper, MIT Sloan School of Management.

Von Hippel, E., and Katz, R. (2002). Shifting Innovation to Users Via Toolkits. Management Science, 48(7), 821-833.

Von Hippel, E. (1998). Economics of product development by users: The impact of "sticky" local information. Management Science, 44(5), 629-644.

Von Hippel, E. (2001). Innovation by user communities: learning from open-source software. (cover story). MIT Sloan Management Review, 42(4), 82-86.

Von Hippel, E. (2005). Democratizing Innovation. Cambridge, MA: MIT Press.

Waltman, L., Van Eck, N.J., and Noyons, E.C.M. (2010). A unified approach to mapping and clustering of bibliometric networks. Journal of Informetrics, 4(4), 629-635.

Waltman, L., and Van Eck, N.J. (2013). A smart local moving algorithm for large-scale modularitybased community detection. European Physical Journal B, 86(11), 471.

Wenger E. (2004). Knowledge management as a doughnut: shaping your knowledge strategy through communities of practice. Business Journal, 68(3), 1-8.

White, H.D. (2003). Pathfinder networks and author cocitation analysis: A remapping of research streamatic information scientists. Journal of the American Society for Information Science and Technology, 54(5), 423-434.

Williamson, O.E., and Winter, S.G. (1991). The Nature of the Firm: Origins, Evolution, and Development. New York: Oxford University Press.

Zahl, S. (1977). Jack-knifing an index of diversity. Ecology, 58(4), 907-913. 
APPENDIX 1. Most cited articles in the set of 155 intellectual core

We identified the articles of the dataset which have been mostly cited by means of the UCINET software. The number of citations per paper was normalized by means of an algorithm that takes into account the "age" of the article (Sidiropoulos et al., 2007). This correction was needed to reduce the time penalty afflicting more recent articles:

$$
S(i, t)=\frac{4}{\left(t-t_{1}+1\right)} C(i, t) ; \quad t \geq t_{1}
$$

Where $t_{l}$ is the publication year of article $i, C(i, t)$ is the number of citations for the article $i$ at time $t$. Thus $S(i, t)$ is the number of citations that article $i$ received normalized by the coefficient 4 . We identified a subset of 27 papers (about $20 \%$ of the total), which received about $80 \%$ of the citations. Below, the distribution of the most cited articles is reported:

\begin{tabular}{lc|lc}
\hline Journal & \# Articles & Journal & \# Articles \\
\hline Organization Science & 4 & MIT Sloan Management Review & 1 \\
J. of Product Innovation Management & 3 & J. of Macromarketing & 1 \\
R \& D Management & 3 & Industrial Marketing Management & 1 \\
California Management Review & 2 & MIS Quarterly & 1 \\
Long Range Planning & 2 & Innovation Management Policy \& Practice & 1 \\
Technovation & 2 & Technology Analysis \& Strategic Management & 1 \\
J. of Management Information Systems & 1 & J. of Business Research & 1 \\
J. of Marketing & 1 & Research Policy & 1 \\
Management Science & 1 & Tot. & 27 \\
\hline
\end{tabular}

APPENDIX 2. Most co-cited references (within 155 intellectual core)

\begin{tabular}{c|lc}
\hline ID & cited reference & Co-citation links \\
\hline 1977 & franke n, 2003, res policy, v32, p155, doi 10.1016/s0048-7333(02)00006-9 & 45 \\
5903 & von hippel e., 2005, democratizing innova & 35 \\
2921 & jeppesen lb, 2006, organ sci, v17, p45, doi 10.1287/orsc.1050.0156 & 34 \\
5860 & von hippel e, 2002, manage sci, v48, p821, doi 10.1287/mnsc.48.7.821.2817 & 31 \\
5902 & von hippel e., 1988, sources innovation & 30 \\
3373 & lakhani kr, 2003, res policy, v32, p923, doi 10.1016/s0048-7333(02)00095-1 & 29 \\
5861 & von hippel e, 2003, organ sci, v14, p209 & 27 \\
4122 & muniz am, 2001, j consum res, v27, p412 & 26 \\
5904 & von hippel e.,2005, democratizing innova & 26 \\
3597 & lilien gl, 2002, manage sci, v48, p1042, doi 10.1287/mnsc.48.8.1042.171 & 25 \\
4993 & sawhney m, 2005, j interact mark, v19, p4, doi 10.1002/dir.20046 & 25 \\
3516 & lerner j, 2002, j ind econ, v50, p197 & 24 \\
4146 & nambisan s, 2002, acad manage rev, v27, p392, doi 10.2307/4134386 & 24 \\
1978 & franke n, 2004, j prod innovat manag, v21, p401, doi 10.1111/j.0737-6782.2004.00094.x & 23 \\
2609 & hertel g, 2003, res policy, v32, p1159, doi 10.1016/s0048-7333(03)00047-7 & 23 \\
4990 & sawhney m, 2000, calif manage rev, v42, p24 & 22 \\
1062 & chesbrough h., 2003, open innovation new & 21 \\
4526 & piller ft, 2006, r\&d manage, v36, p307, doi 10.1111/j.1467-9310.2006.00432.x & 21 \\
1181 & cohen wm, 1990, admin sci quart, v35, p128, doi 10.2307/2393553
\end{tabular}




\begin{tabular}{l|ll}
\hline 3890 & mcalexander jh, 2002, j marketing, v66, p38, doi 10.1509/jmkg.66.1.38.18451 & 20 \\
5147 & shah sk, 2006, manage sci, v52, p1000, doi 10.1287/mnsc.1060.0553 & 20 \\
5556 & thomke s, 2002, harvard bus rev, v80, p74 & 20 \\
\hline
\end{tabular}

APPENDIX 3. Most co-cited pairs (top 20)

\begin{tabular}{|c|c|c|c|}
\hline$I D_{i}$ & Reference $_{i}$ * & $I D_{j}$ & Reference $_{j}$ * \\
\hline 161 & allen t., 1984, managing flow techno & 5554 & $\begin{array}{l}\text { thomke s, 2000, j prod innovat manag, v17, p128, } \\
\text { doi 10.1016/s0737-6782(99)00031-4 }\end{array}$ \\
\hline 663 & $\begin{array}{l}\text { bjelland o. m., 2008, mit sloan manage rev, v50, } \\
\text { p31 }\end{array}$ & 1251 & $\begin{array}{l}\text { corrocher } \mathrm{n}, 2011 \text {, technol forecast soc, } \mathrm{v} 78, \mathrm{p} 547 \text {, } \\
\text { doi } 10.1016 / \mathrm{j} . \text { techfore. } 2010.10 .006\end{array}$ \\
\hline 2088 & gallaugher j, 2010, mis q exec, v9, p197 & 2454 & hansen mt, 2007, harvard bus rev, v85, p121 \\
\hline 2454 & hansen mt, 2007, harvard bus rev, v85, p121 & 3616 & linder jc, 2003, mit sloan manage rev, v44, p43 \\
\hline 663 & $\begin{array}{l}\text { bjelland o. m., 2008, mit sloan manage rev, v50, } \\
\text { p31 }\end{array}$ & 1222 & cooke $\mathrm{m}, 2008$, int j market res, v50, p267 \\
\hline 822 & $\begin{array}{l}\text { brown la, 1991, cytopathology, v2, p1, doi } \\
10.1111 / \text { j.1365-2303.1991.tb00377.x }\end{array}$ & 5062 & schrage m., 2000, serious play worlds \\
\hline 1222 & cooke m, 2008, int j market res, v50, p267 & 1251 & $\begin{array}{l}\text { corrocher } \mathrm{n}, 2011 \text {, technol forecast soc, } \mathrm{v} 78 \text {, p547, } \\
\text { doi } 10.1016 / \text { j.techfore. } 2010.10 .006\end{array}$ \\
\hline 2454 & hansen mt, 2007, harvard bus rev, v85, p121 & 3076 & kelley sw, 1990, j retailing, v66, p315 \\
\hline 152 & $\begin{array}{l}\text { alexy o, 2012, calif manage rev, v54, p116, doi } \\
10.1525 / \mathrm{cmr} .2012 .54 .3 .116\end{array}$ & 2454 & hansen $\mathrm{mt}, 2007$, harvard bus rev, v85, p121 \\
\hline 271 & $\begin{array}{l}\text { aral s, 2011, manage sci, v57, p1623, doi } \\
10.1287 / \mathrm{mnsc} .1110 .1421\end{array}$ & 1502 & $\begin{array}{l}\text { dellarocas c, 2010, j manage inform syst, v27, p127, } \\
\text { doi } 10.2753 / \text { mis } 0742-1222270204\end{array}$ \\
\hline 271 & $\begin{array}{l}\text { aral s, 2011, manage sci, v57, p1623, doi } \\
10.1287 / \mathrm{mnsc} .1110 .1421\end{array}$ & 5165 & shapiro c, 1998, inform rules strateg \\
\hline 1502 & $\begin{array}{l}\text { dellarocas c, 2010, j manage inform syst, v27, } \\
\text { p127, doi } 10.2753 / \text { mis0742-1222270204 }\end{array}$ & 5165 & shapiro c, 1998, inform rules strateg \\
\hline 3543 & $\begin{array}{l}\text { levy m, 2009, j knowl manag, v13, p120, doi } \\
10.1108 / 13673270910931215\end{array}$ & 4803 & $\begin{array}{l}\text { riegner c, } 2007, \mathrm{j} \text { advertising res, } \mathrm{v} 47, \mathrm{p} 436 \text {, doi } \\
10.2501 / \mathrm{s} 0021849907070456\end{array}$ \\
\hline 891 & burt r. s., 1992, structural holes soc & 3496 & leonard d., 1999, sparks fly igniting \\
\hline 891 & burt r. s., 1992, structural holes soc & 5827 & $\begin{array}{l}\text { verona g., 2002, european management, v20, p299, } \\
\text { doi } 10.1016 / \mathrm{s} 0263-2373(02) 00046-4\end{array}$ \\
\hline 2088 & gallaugher j, 2010, mis q exec, v9, p197 & 3616 & linder jc, 2003, mit sloan manage rev, v44, p43 \\
\hline 4770 & $\begin{array}{l}\text { resnik aj, 1983, j marketing, v47, p86, doi } \\
10.2307 / 3203430\end{array}$ & 5567 & $\begin{array}{l}\text { thompson cj, 1997, j marketing res, v34, p438, doi } \\
10.2307 / 3151963\end{array}$ \\
\hline 822 & $\begin{array}{l}\text { brown la, 1991, cytopathology, v2, p1, doi } \\
\text { 10.1111/j.1365-2303.1991.tb00377.x }\end{array}$ & 4219 & nonaka i, 1998, calif manage rev, v40, p40 \\
\hline 3543 & $\begin{array}{l}\text { levy m, 2009, j knowl manag, v13, p120, doi } \\
10.1108 / 13673270910931215\end{array}$ & 3888 & mcafee ap, 2006, mit sloan manage rev, v47, p21 \\
\hline 3888 & mcafee ap, 2006, mit sloan manage rev, v47, p21 & 4803 & $\begin{array}{l}\text { riegner c, 2007, j advertising res, } \mathrm{v} 47, \mathrm{p} 436 \text {, doi } \\
10.2501 / \mathrm{s} 0021849907070456\end{array}$ \\
\hline
\end{tabular}

*VOSviewer reports only the first author of the extracted reference

APPENDIX 4. Cluster 1 "Organizational Learning"

\begin{tabular}{|c|c|c|}
\hline$I D_{C L 1}$ & ReferenceCL1* & Co-citation links \\
\hline 4990 & sawhney m, 2000, calif manage rev, v42, p24 & 22 \\
\hline 817 & brown js, 1991, organ sci, v2, p40, doi 10.1287/orsc.2.1.40 & 14 \\
\hline 3992 & miles mb, 1994, qualitative data ana & 11 \\
\hline 5982 & wasko $\mathrm{mm}, 2005$, mis quart, v29, p35 & 11 \\
\hline 3191 & kogut b, 1992, organ sci, v3, p383, doi 10.1287/orsc.3.3.383 & 10 \\
\hline
\end{tabular}




\begin{tabular}{l|ll}
\hline 3804 & march jg, 1991, organ sci, v2, p71, doi 10.1287/orsc.2.1.71 & 10 \\
6188 & yin r., 2003, case study res desig & 10 \\
\hline
\end{tabular}

*In a cluster made of 169 references, only references with co-citations links $\geq 10$ are reported.

APPENDIX 5. Cluster 2 "Open and Distributed Innovation"

\begin{tabular}{r|lc}
\hline IDCL5 & ReferencecL5 $*$ & Co-citation links \\
\hline 5903 & von hippel e., 2005, democratizing innova & 35 \\
5860 & von hippel e, 2002, manage sci, v48, p821, doi 10.1287/mnsc.48.7.821.2817 & 31 \\
4146 & nambisan s, 2002, acad manage rev, v27, p392, doi 10.2307/4134386 & 24 \\
1062 & chesbrough h., 2003, open innovation new & 21 \\
1980 & franke n, 2006, j prod innovat manag, v23, p301, doi 10.1111/j.1540-5885.2006.00203.x & 17 \\
2748 & howe j., 2008, crowdsourcing why po & 16 \\
1358 & dahan e, 2002, j prod innovat manag, v19, p332, doi 10.1111/1540-5885.1950332 \\
2053 & fuller j, 2010, calif manage rev, v52, p98 & 16 \\
3433 & laursen k, 2006, strategic manage j, v27, p131, doi 10.1002/smj.507 & 14 \\
3200 & kohler t, 2009, technovation, v29, p395, doi 10.1016/j.technovation.2008.11.004 & 14 \\
2924 & jeppesen lb, 2010, organ sci, v21, p1016, doi 10.1287/orsc.1090.0491 & 14 \\
2920 & jeppesen lb, 2005, j prod innovat manag, v22, p347, doi 10.1111/j.0737-6782.2005.00131.x & 13 \\
4628 & prahalad c. k., 2004, future competition c & 13 \\
2049 & fuller j, 2007, technovation, v27, p378, doi 10.1016/j.technovation.2006.09.005 \\
1682 & ebner w, 2009, r\&d manage, v39, p342, doi 10.1111/j.1467-9310.2009.00564.x & 13 \\
4300 & ogawa s, 2006, mit sloan manage rev, v47, p65 & 12 \\
6044 & west j, 2008, ind innov, v15, p223, doi 10.1080/13662710802033734 & 11 \\
3694 & luthje c, 2004, technovation, v24, p683, doi 10.1016/s0166-4972(02)00150-5 \\
1375 & dahlander 1, 2010, res policy, v39, p699, doi 10.1016/j.respol.2010.01.013 & 11 \\
2807 & huston 1, 2006, harvard bus rev, v84, p58 & 11 \\
4742 & raymond e, 1999, cathedral bazaar mus & 11
\end{tabular}

*In a cluster made of 239 references, only references with co-citations links $\geq 10$ are reported. Original clusters 2 and 6 were joined forming Cluster 2.

APPENDIX 6. Cluster 3 "Value (Co)creation"

\begin{tabular}{r|lc}
\hline IDCL3 & ReferenceCL3 & Co-citation links \\
\hline 3373 & lakhani kr, 2003, res policy, v32, p923, doi 10.1016/s0048-7333(02)00095-1 & 29 \\
4122 & muniz am, 2001, j consum res, v27, p412 & 26 \\
4993 & sawhney m, 2005, j interact mark, v19, p4, doi 10.1002/dir.20046 & 25 \\
1978 & franke n, 2004, j prod innovat manag, v21, p401, doi 10.1111/j.0737-6782.2004.00094.x & 23 \\
3890 & mcalexander jh, 2002, j marketing, v66, p38, doi 10.1509/jmkg.66.1.38.18451 & 20 \\
3251 & kozinets rv, 2002, j marketing res, v39, p61, doi 10.1509/jmkr.39.1.61.18935 & 19 \\
1943 & fornell c, 1981, j marketing res, v18, p39, doi 10.2307/3151312 & 19 \\
2047 & fuller j, 2007, j bus res, v60, p60, doi 10.1016/j.jbusres.2006.09.019 & 18 \\
2474 & harhoff d, 2003, res policy, v32, p1753, doi 10.1016/s0048-7333(03)00061-1 & 18 \\
2918 & jeppesen lb, 2003, technol anal strateg, v15, p363, doi 10.1080/09537320310001601531 & 18 \\
2065 & fuller j., 2006, electronic commerce research, v6, doi 10.1007/s10660-006-5988-7 & 18 \\
4123 & muniz am, 2005, j consum res, v31, p737, doi 10.1086/426607 & 15 \\
\hline
\end{tabular}




\begin{tabular}{r|lc}
\hline 5797 & vargo sl, 2004, j marketing, v68, p1, doi 10.1509/jmkg.68.1.1.24036 & 15 \\
154 & algesheimer r, 2005, j marketing, v69, p19, doi 10.1509/jmkg.69.3.19.66363 & 13 \\
309 & armstrong js, 1977, j marketing res, v14, p396, doi 10.2307/3150783 & 12 \\
5981 & wasko mm, 2000, j strategic inf syst, v9, p155 & 12 \\
1210 & constant d, 1996, organ sci, v7, p1 19, doi 10.1287/orsc.7.2.119 & 11 \\
2408 & hagel j., 1997, net gain expanding m & 11 \\
2680 & hoffman dl, 1996, j marketing, v60, p50, doi 10.2307/1251841 & 11 \\
2050 & fuller j, 2008, j prod innovat manag, v25, p608, doi 10.1111/j.1540-5885.2008.00325.x & 11 \\
5017 & schau hj, 2009, j marketing, v73, p30 & 11 \\
4637 & prahalad ck, 2000, harvard bus rev, v78, p79 & 10 \\
1548 & dholakia um, 2004, int j res mark, v21, p241, doi 10.1016/j.ijresmar.2003.12.004 \\
402 & bagozzi rp, 2006, int j res mark, v23, p45, doi 10.1016/j.ijresmar.2006.01.005 & 10 \\
\hline
\end{tabular}

*In a cluster made of 293 references, only references with co-citations links $\geq 10$ are reported. Original clusters 3, 4 and 9 were joined forming Cluster 3.

APPENDIX 7. Cluster 4 "User/Customer Involvement in Innovation Processes"

\begin{tabular}{|c|c|c|}
\hline$I D_{C L 5}$ & ReferenceCL5* & Co-citation links \\
\hline 1977 & franke $n, 2003$, res policy, v32, p155, doi 10.1016/s0048-7333(02)00006-9 & 45 \\
\hline 5902 & von hippel e., 1988, sources innovation & 30 \\
\hline 3597 & lilien gl, 2002, manage sci, v48, p1042, doi 10.1287/mnsc.48.8.1042.171 & 25 \\
\hline 1181 & cohen wm, 1990, admin sci quart, v35, p128, doi 10.2307/2393553 & 20 \\
\hline 5556 & thomke s, 2002, harvard bus rev, v80, p74 & 20 \\
\hline 5719 & urban $\mathrm{gl}, 1988$, manage sci, v34, p569, doi 10.1287/mnsc.34.5.569 & 19 \\
\hline 5858 & von hippel e, 2001, j prod innovat manag, v18, p247, doi 10.1016/s0737-6782(01)00090-x & 19 \\
\hline 1714 & eisenhardt km, 1989, acad manage rev, v14, p532, doi 10.2307/258557 & 17 \\
\hline 4089 & morrison pd, 2000, manage sci, v46, p1513, doi 10.1287/mnsc.46.12.1513.12076 & 15 \\
\hline 5869 & von hippel e,1986, manage sci, v32, p791, doi 10.1287/mnsc.32.7.791 & 15 \\
\hline 2603 & herstatt c, 1992, j prod innovat manag, v9, p213, doi 10.1016/0737-6782(92)90031-7 & 14 \\
\hline 5925 & vonhippel e, 1986, manage sci, v32, p791, doi 10.1287/mnsc.32.7.791 & 13 \\
\hline 5856 & von hippel e, 1998, manage sci, v44, p629, doi 10.1287/mnsc.44.5.629 & 12 \\
\hline 5926 & vonhippel e, 1994, manage sci, v40, p429, doi 10.1287/mnsc.40.4.429 & 12 \\
\hline 2355 & gruner ke, 2000, j bus res, v49, p1, doi 10.1016/s0148-2963(99)00013-2 & 11 \\
\hline 1976 & franke n, 2003, res policy, v32, p1199, doi 10.1016/s0048-7333(03)00049-0 & 10 \\
\hline 5881 & von hippel e,1994, manage sci, v40, p429, doi 10.1287/mnsc.40.4.429 & 10 \\
\hline 6192 & yin rk, 1994, case study res desig & 10 \\
\hline
\end{tabular}

*In a cluster made of 155 references, only references with co-citations links $\geq 10$ are reported. Original clusters 5 and 11 were joined forming Cluster 5.

APPENDIX 8. Cluster 5 "Knowledge Sharing in Communities"

\begin{tabular}{r|lc}
\hline ID $_{\text {CL6 }}$ & ReferenceCL6 $^{*}$ & Co-citation links \\
\hline 2921 & jeppesen lb, 2006, organ sci, v17, p45, doi 10.1287/orsc.1050.0156 & 34 \\
5861 & von hippel e, 2003, organ sci, v14, p209 & 27 \\
5904 & von hippel e.,2005, democratizing innova & 26 \\
3516 & lerner j, 2002, j ind econ, v50, p197 & 24 \\
2609 & hertel g, 2003, res policy, v32, p1159, doi 10.1016/s0048-7333(03)00047-7 & 23 \\
\hline
\end{tabular}




\begin{tabular}{r|lc}
\hline 5147 & shah sk, 2006, manage sci, v52, p1000, doi 10.1287/mnsc.1060.0553 & 20 \\
5914 & von krogh g, 2006, manage sci, v52, p975, doi 10.1287/mnsc.1060.0560 & 13 \\
2491 & hars a, 2002, int j electron comm, v6, p25 & 12 \\
4090 & morrison pd, 2004, res policy, v33, p351, doi 10.1016/j.respol.2003.09.007 & 11 \\
\hline
\end{tabular}

*In a cluster made of 155 references, only references with co-citations links $\geq 10$ are reported. Original clusters 7, 10 and 12 were joined forming Cluster 6 . 


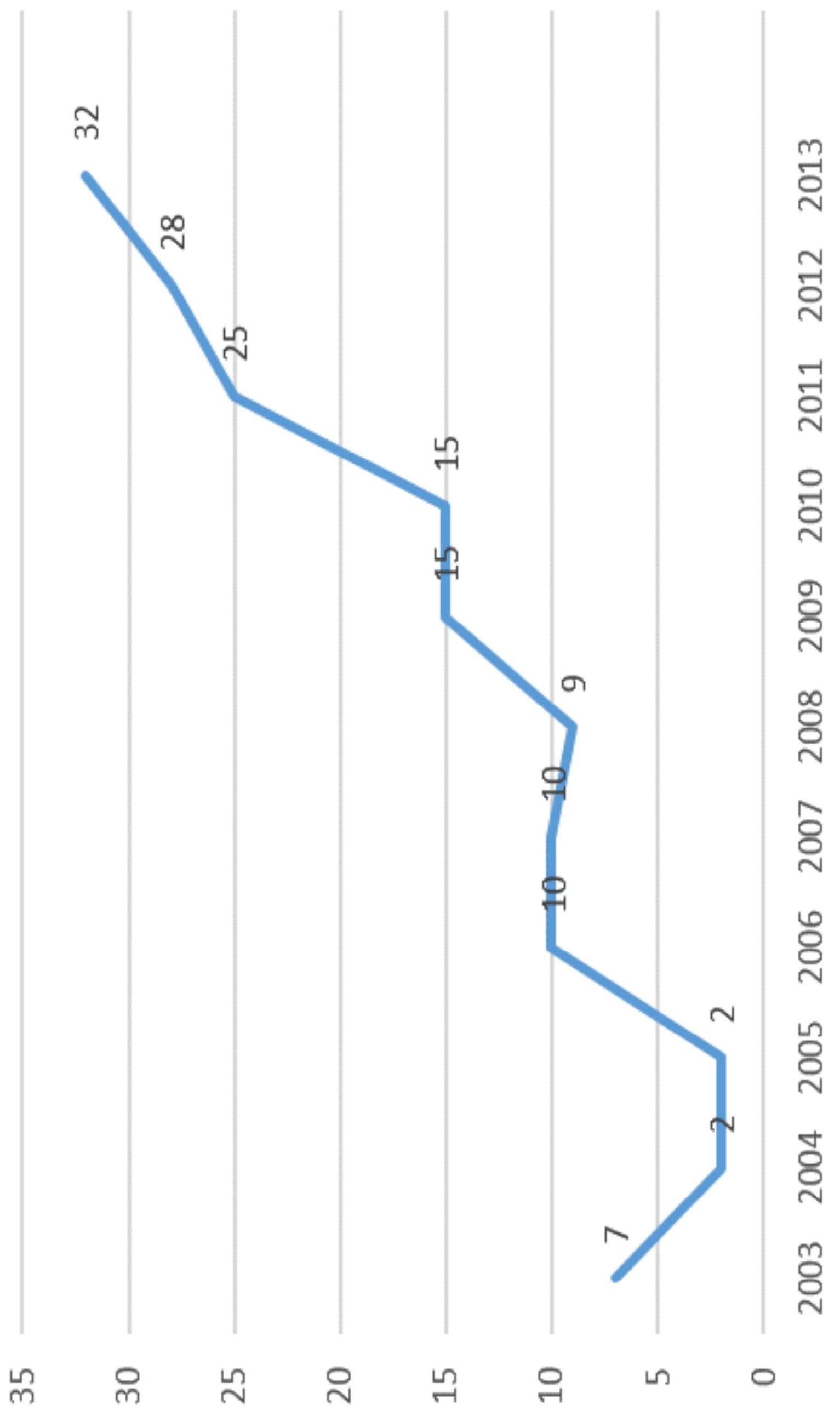




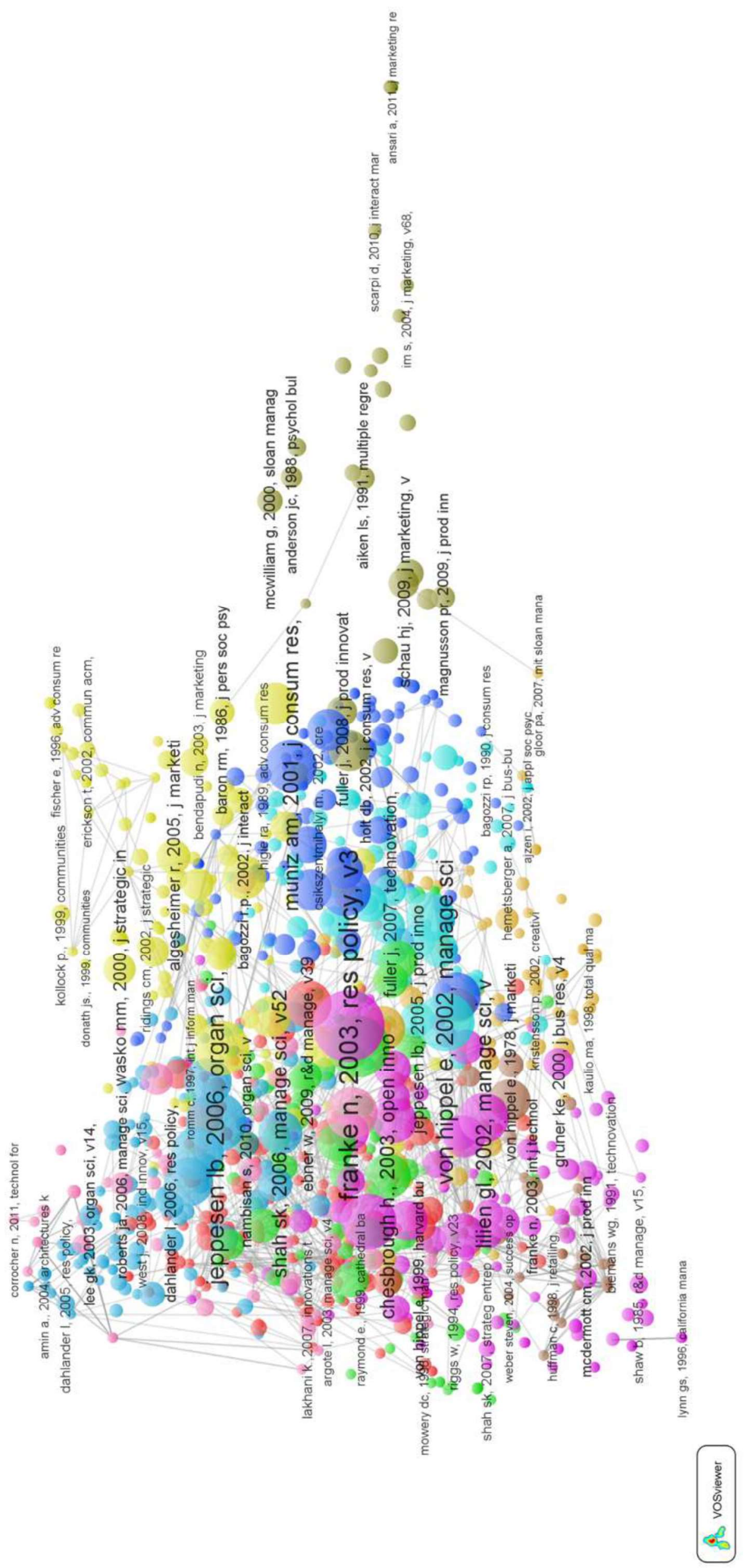




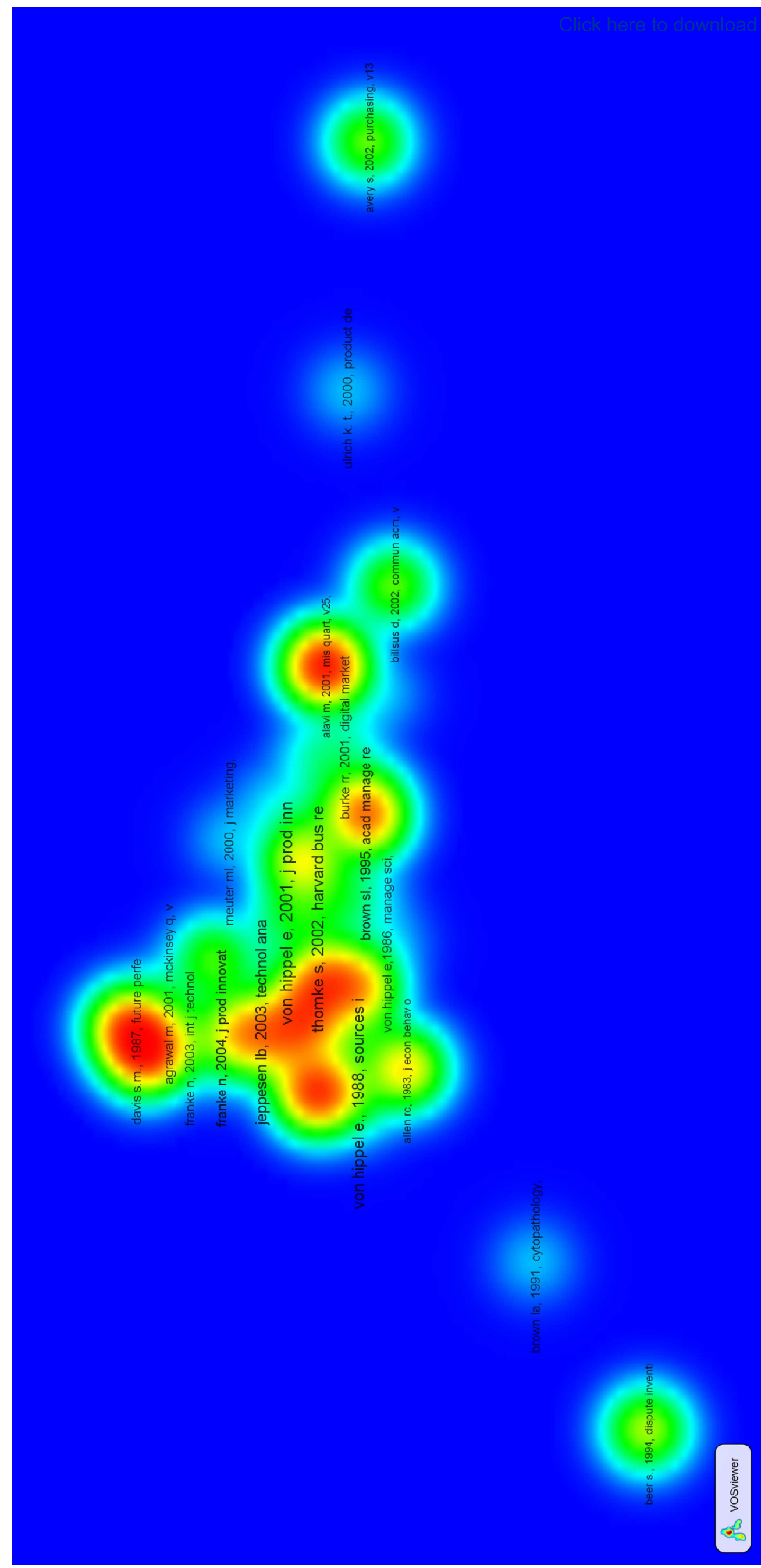

Figure FIGURE3.eps $\underline{\underline{\boldsymbol{t}}}$ 

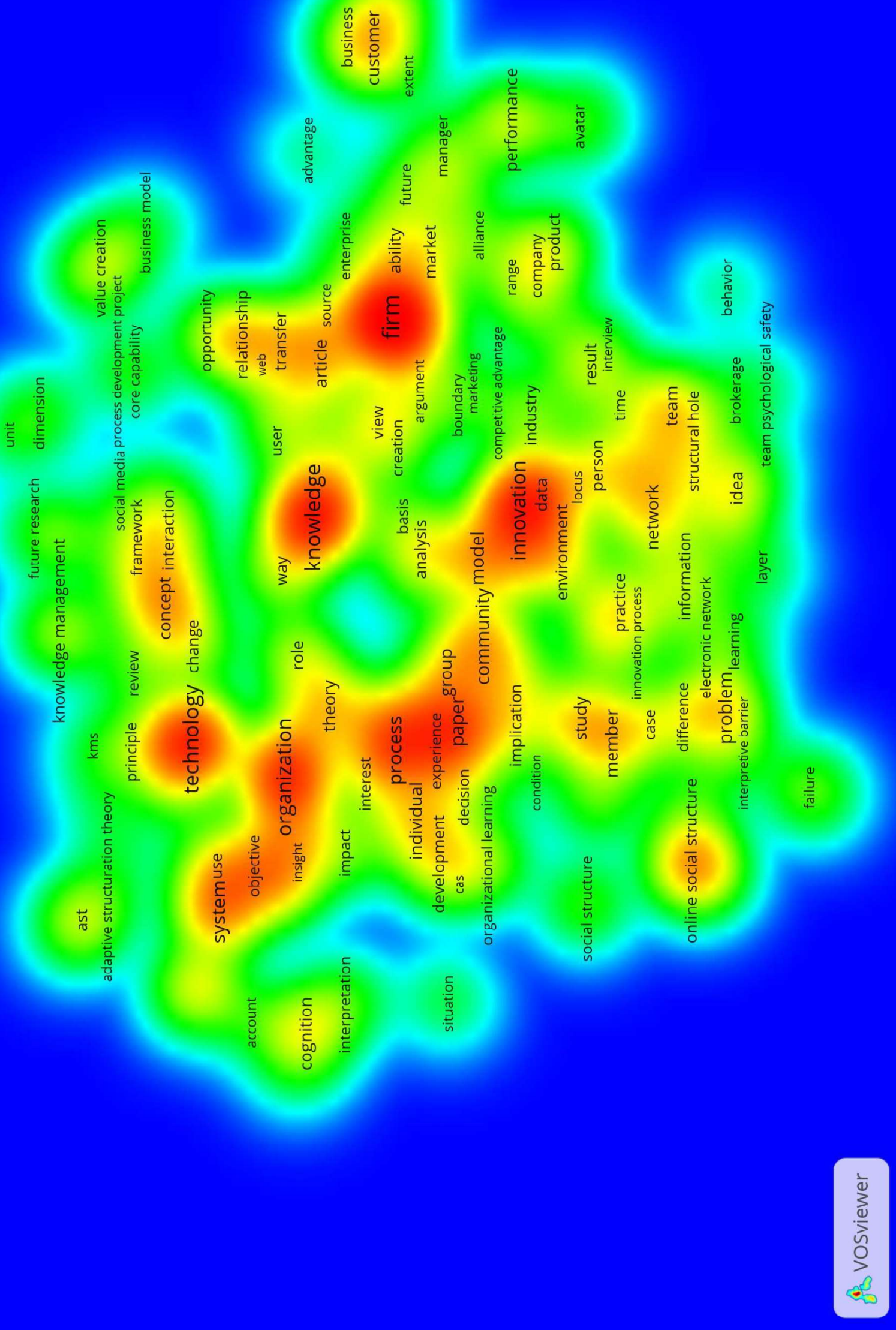


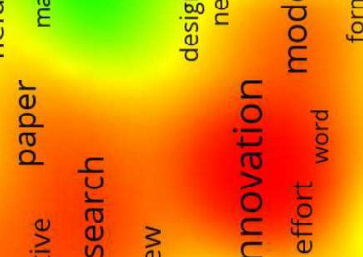

$\frac{\frac{n}{n+\frac{n}{n}}}{\frac{n}{\frac{\pi}{n}}}$

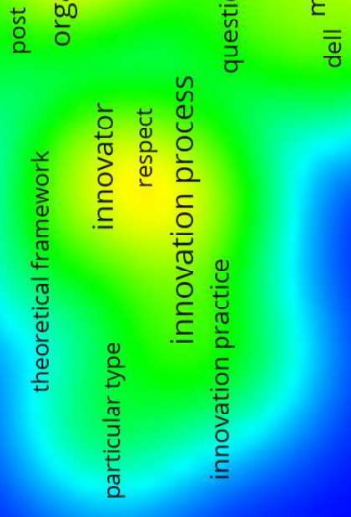




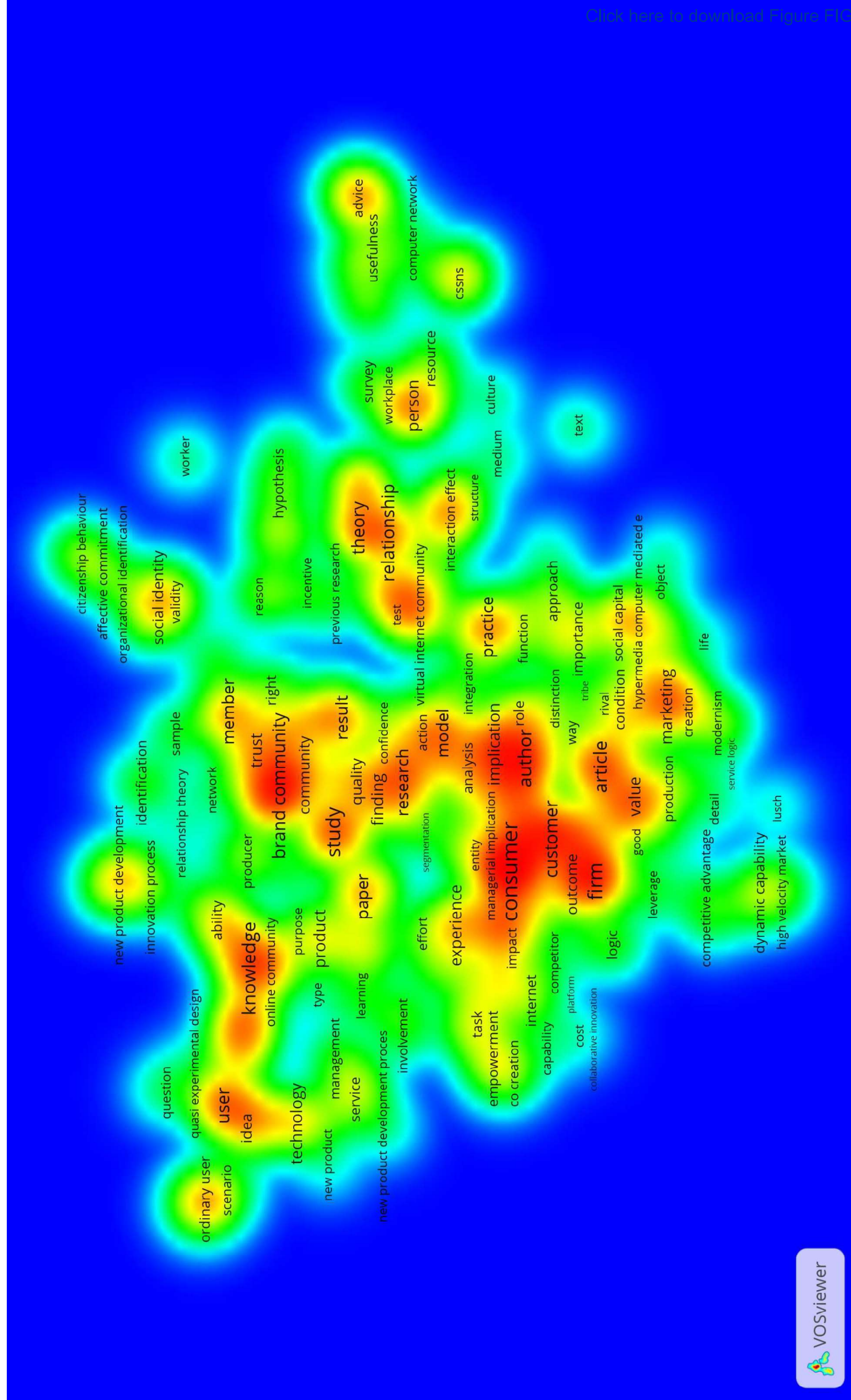




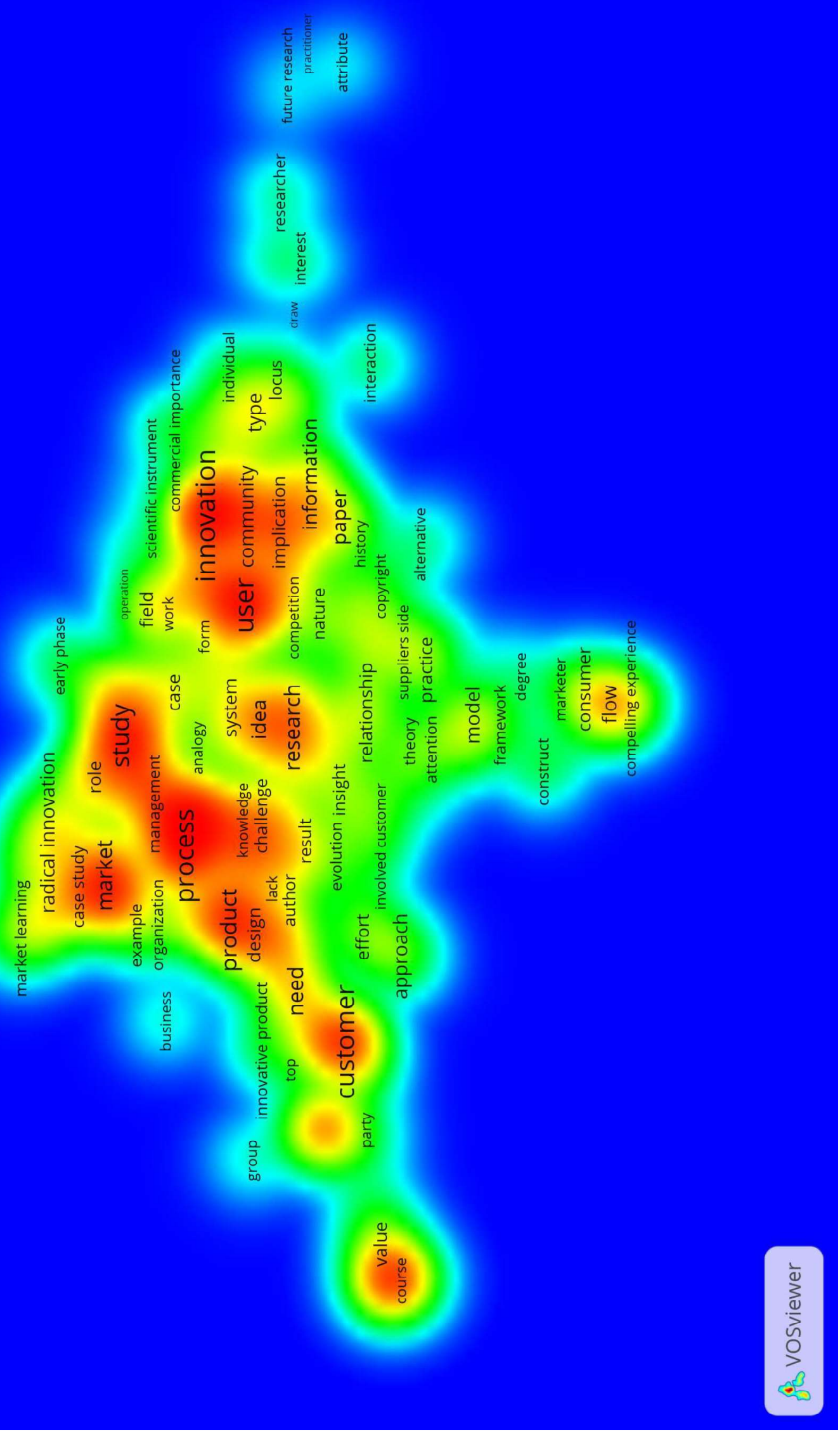




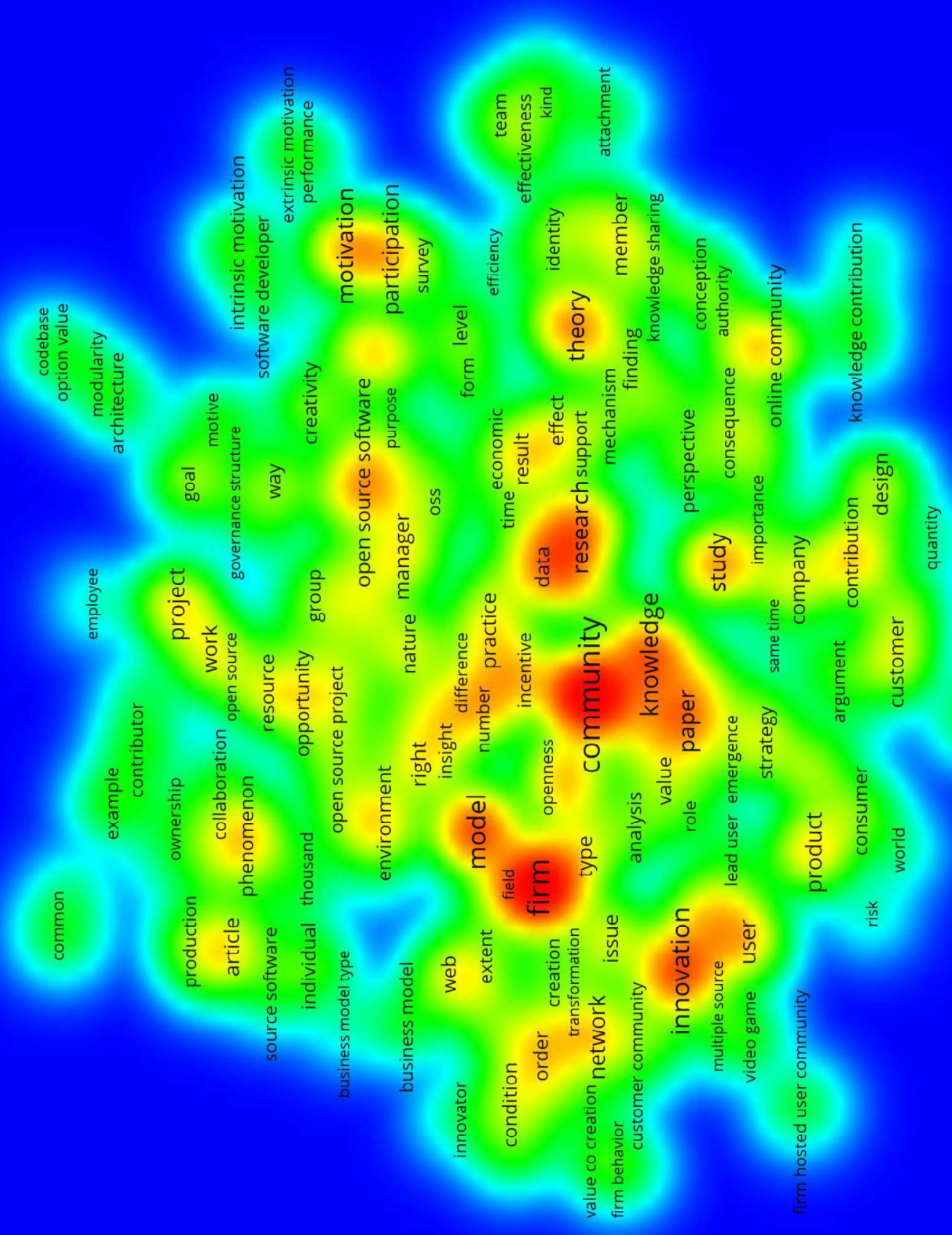




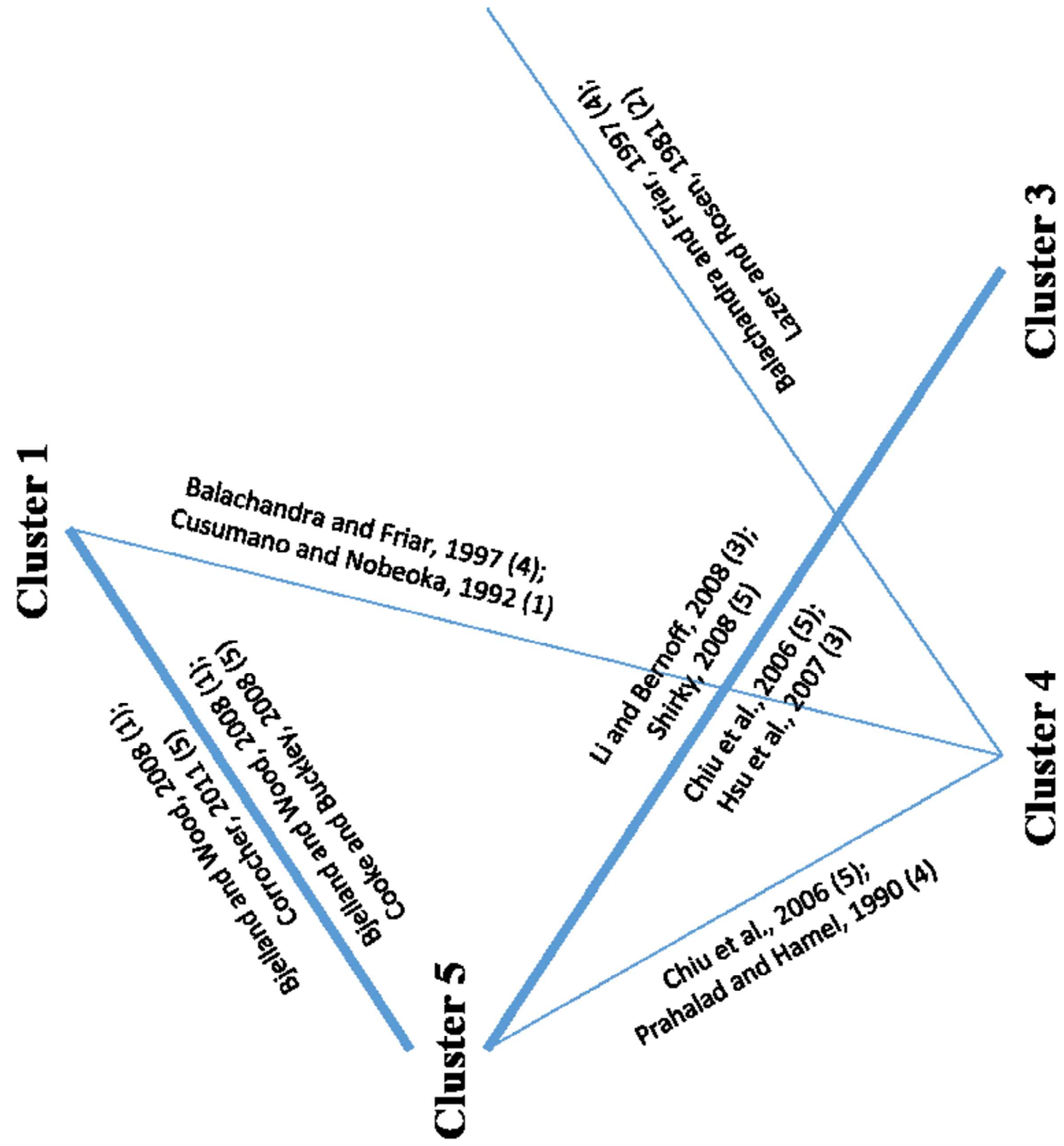




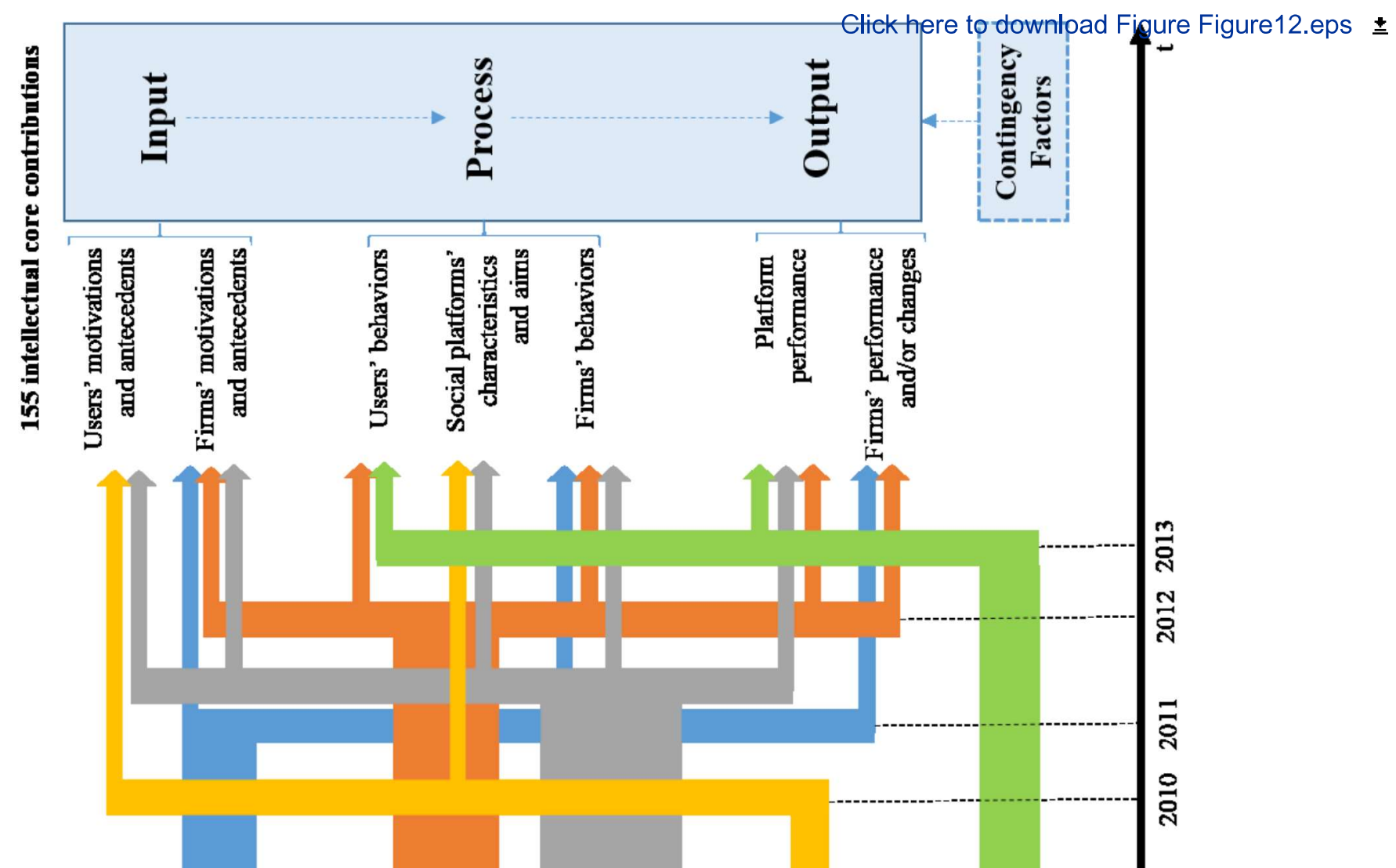

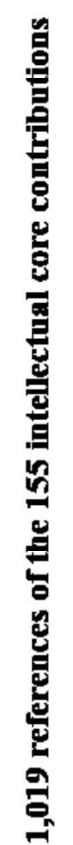

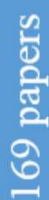

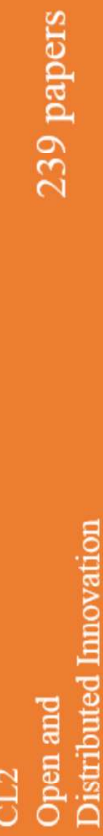
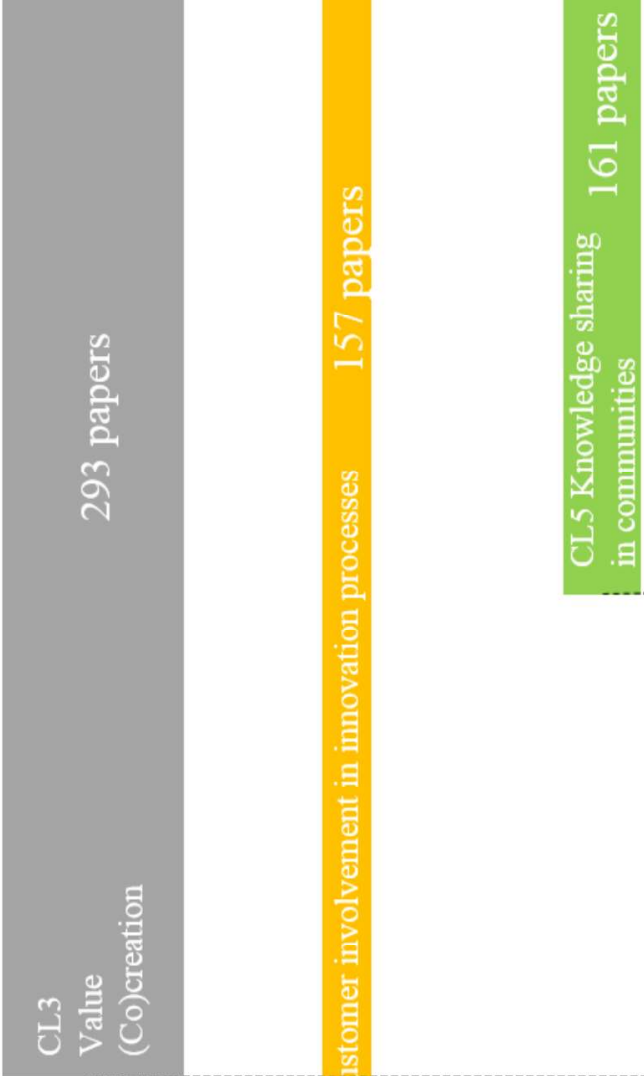

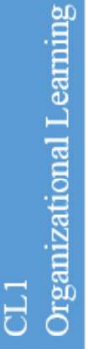

$\infty$
2
$\vdots$
$\vdots$
$\vdots$

ฒ 


\title{
Unveiling the Intellectual Origins of Social Media-based Innovation: insights from a bibliometric approach
}

\author{
Francesco Paolo Appio \\ Léonard de Vinci (Business Lab) \\ Pôle Universitaire, \\ 12 av. Leonard de Vinci, \\ La Défense cedex, 92916 - Paris (France) \\ Email: francesco.appio@devinci.fr \\ Antonella Martini \\ School of Engineering (DESTEC) \\ University of Pisa \\ L.go L. Lazzarino, 56122 - Pisa (Italy) \\ a.martini@ing.unipi.it \\ Silvia Massa \\ University of Genova (DIME) \\ Via All'Opera Pia, 15, 16146 - Genova (Italy) \\ silvia.massa@unige.it \\ Stefania Testa \\ University of Genova (DIME) \\ Via All'Opera Pia, 15, 16146 - Genova (Italy) \\ stefania.testa@unige.it
}

\begin{abstract}
This article uses a bundle of bibliometric and text-mining techniques to provide a systematic assessment of the intellectual core of the Social Media-based innovation research field. The goal of this study is to identify main research areas, understand the current state of development and suggest potential future directions by analysing co-citations from 155 papers published between 2003 and 2013 in the most influential academic journals. The main clusters have been identified, mapped, and labelled. Their most active areas on this topic and the most influential and co-cited papers have been identified and described. Also, intra- and inter-cluster knowledge base diversity has been assessed by using indicators stemming from the domains of Information Theory and Biology. A t-test has been performed to assess the significance of the inter-cluster diversity. Five co-existing research streams shaping the research field under investigation have been identified and characterized.
\end{abstract}

Keywords: Social Media, innovation, bibliometric analysis, content analysis, diversity analysis

Mathematics Subject Classification: 91-02

JEL codes: O32, M15 


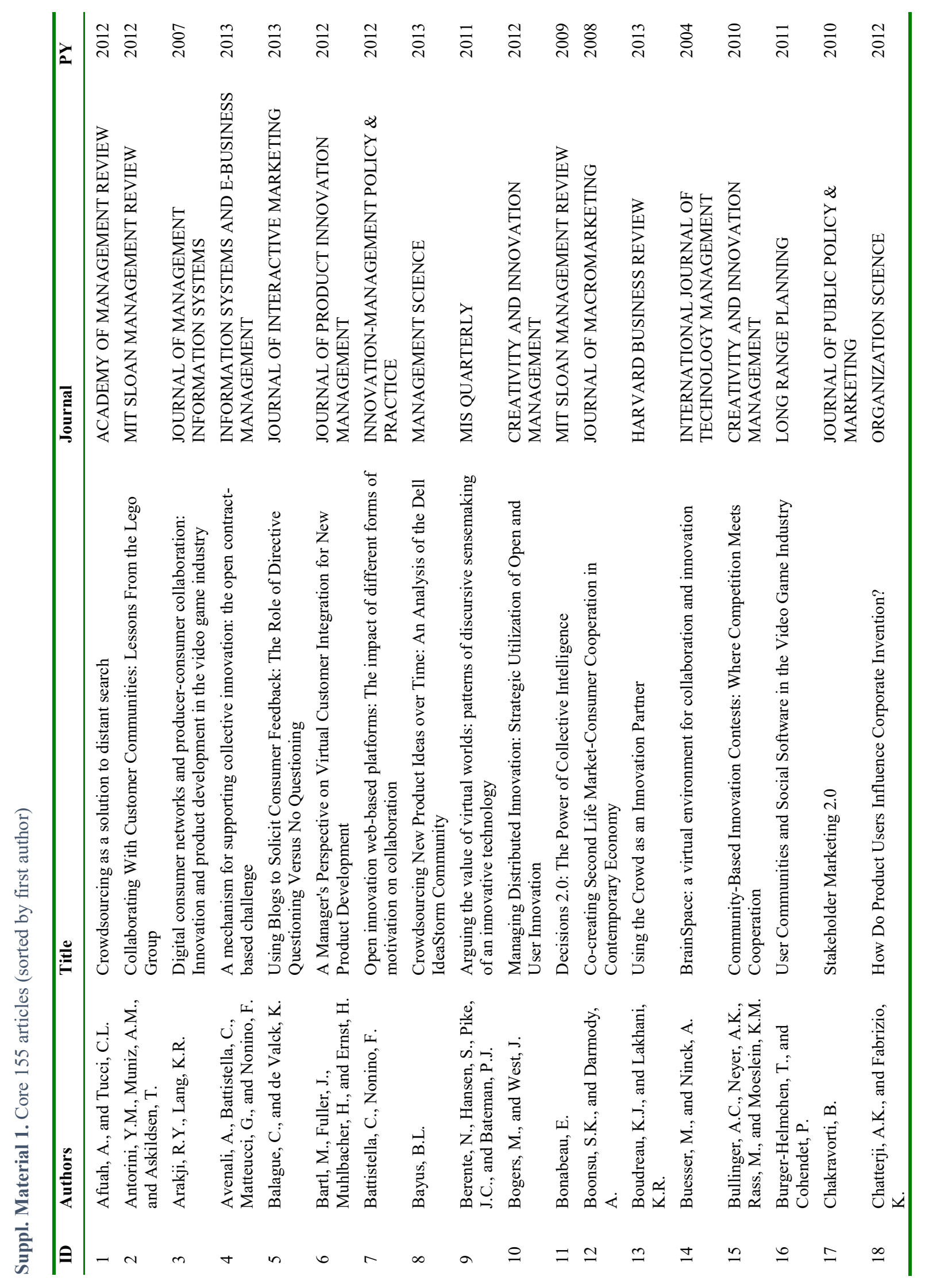




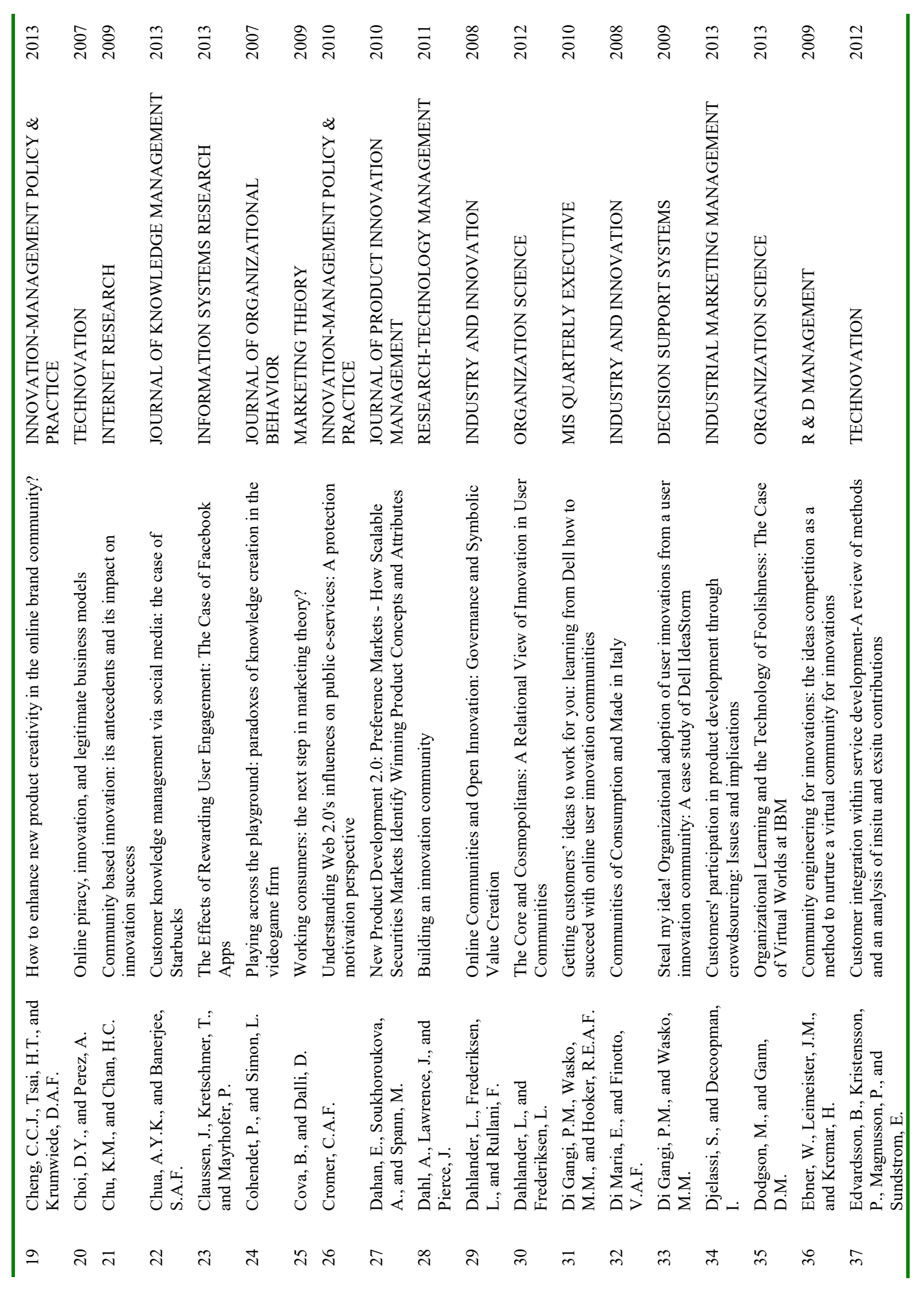




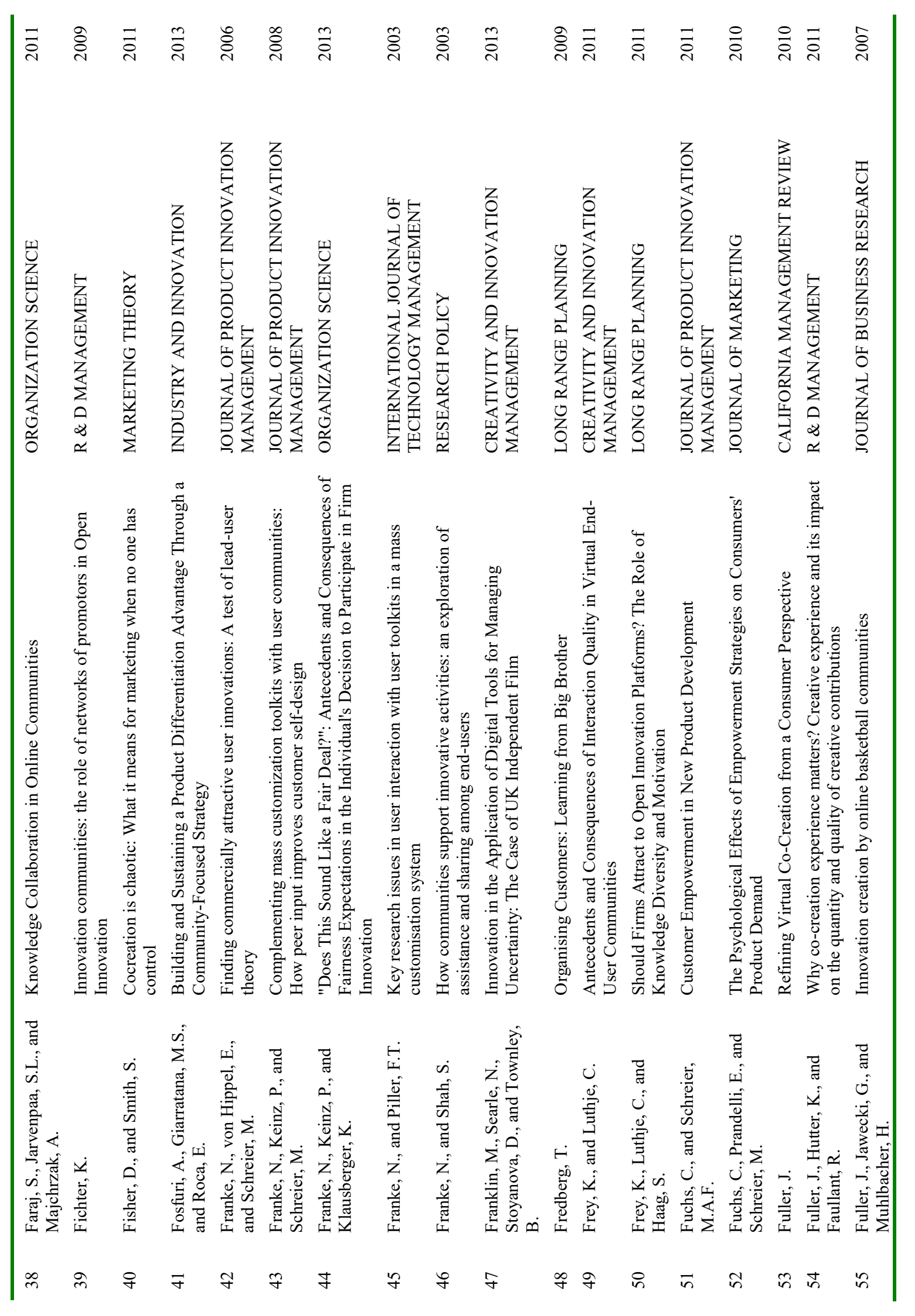




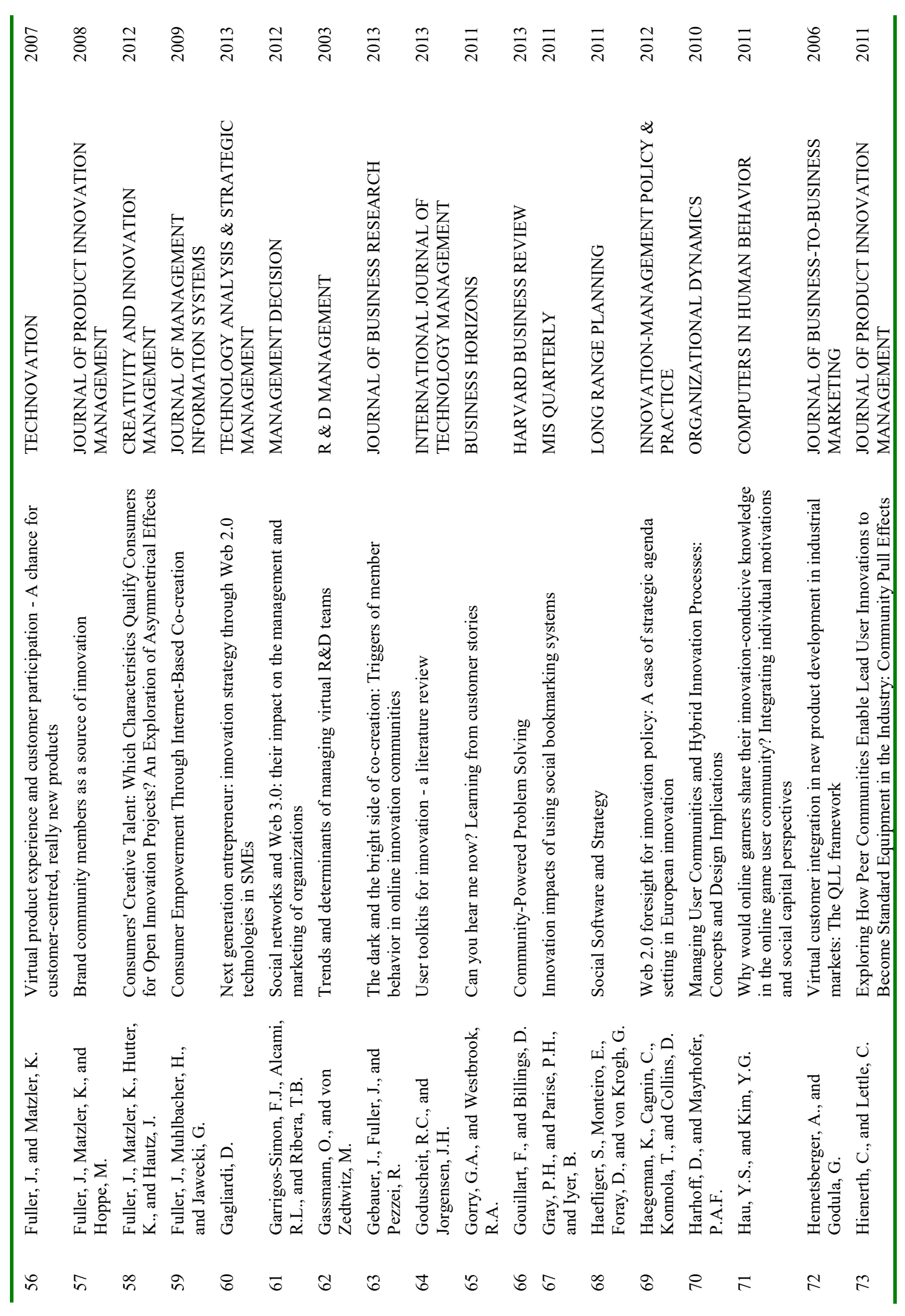




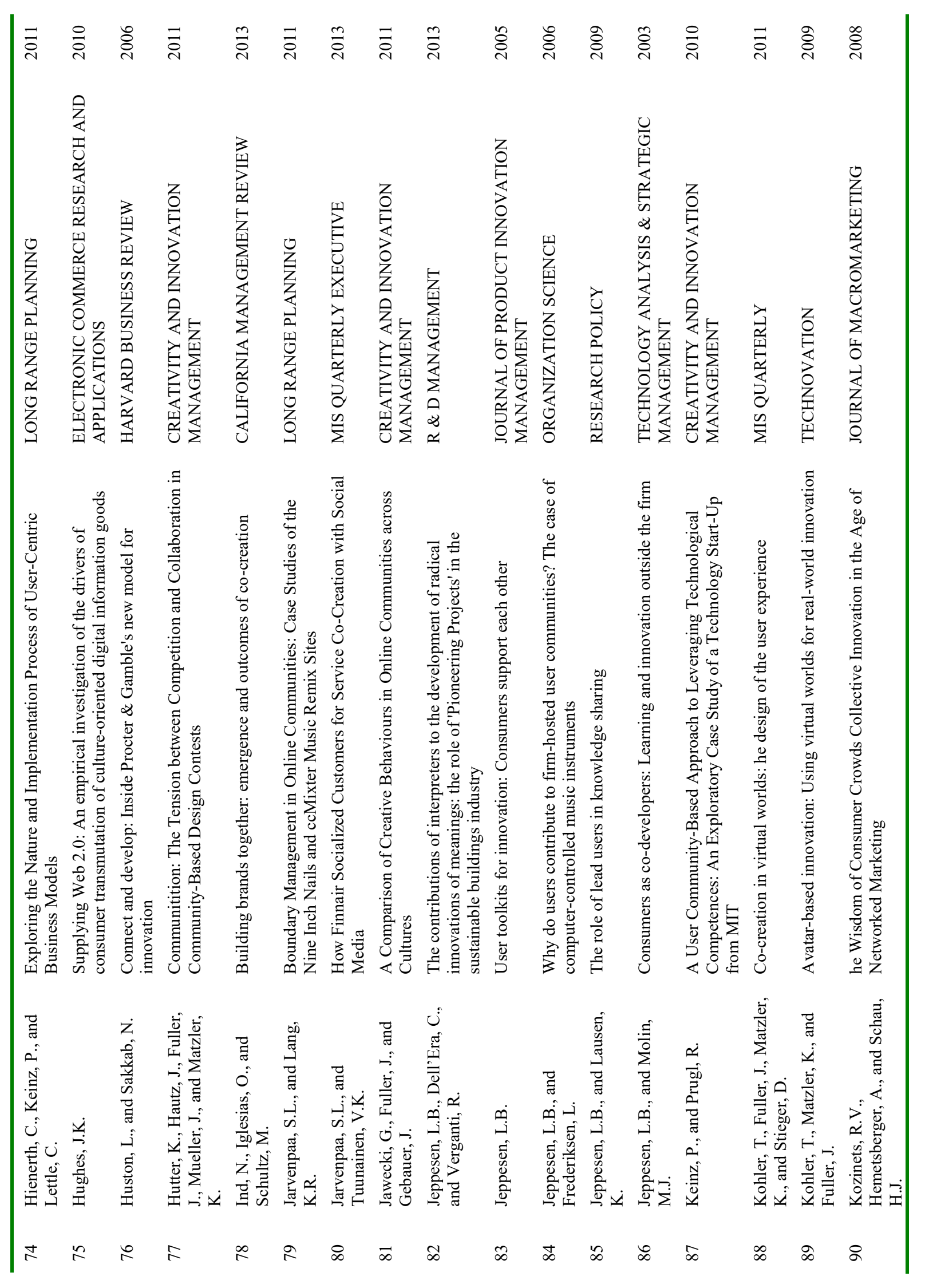




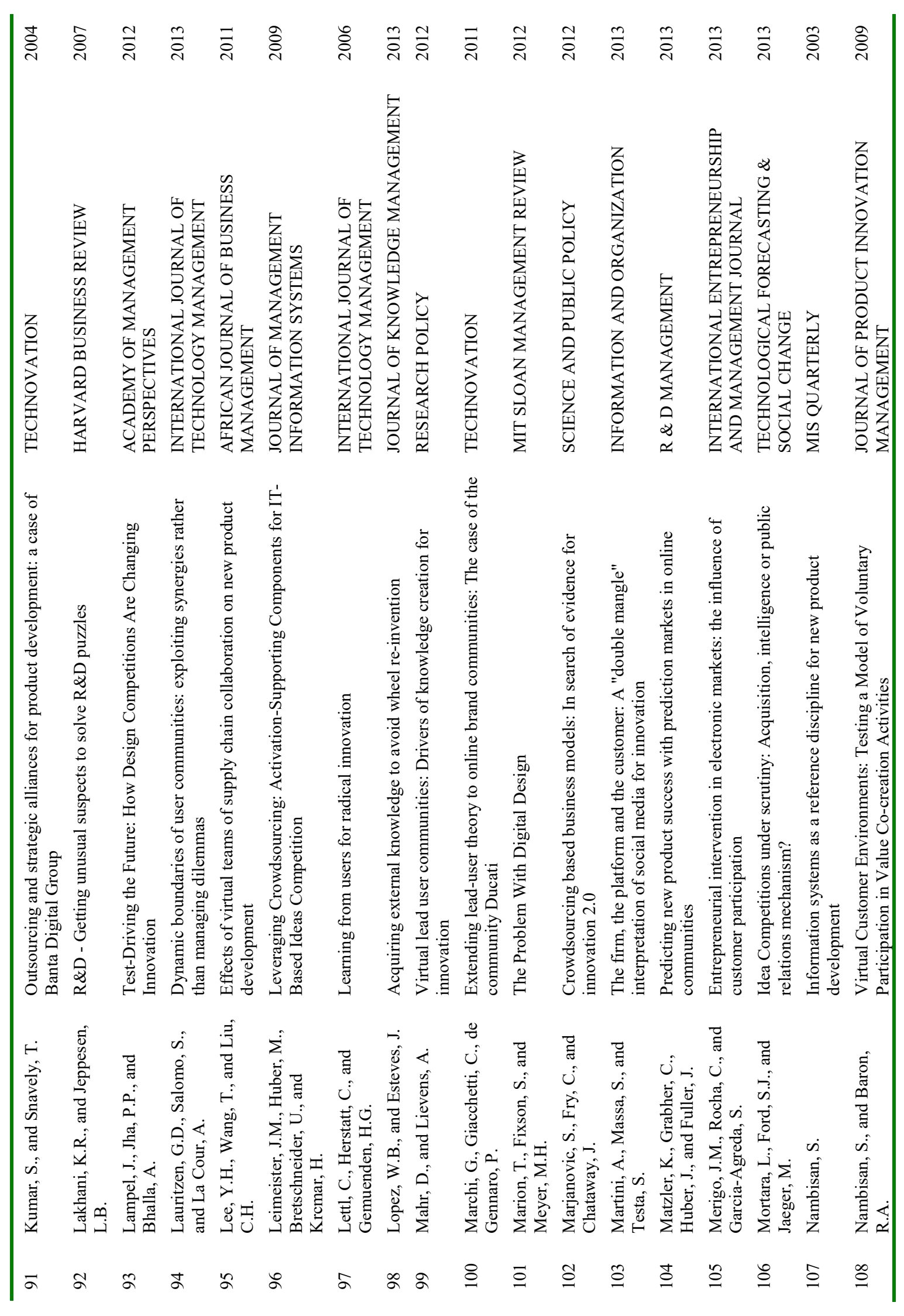




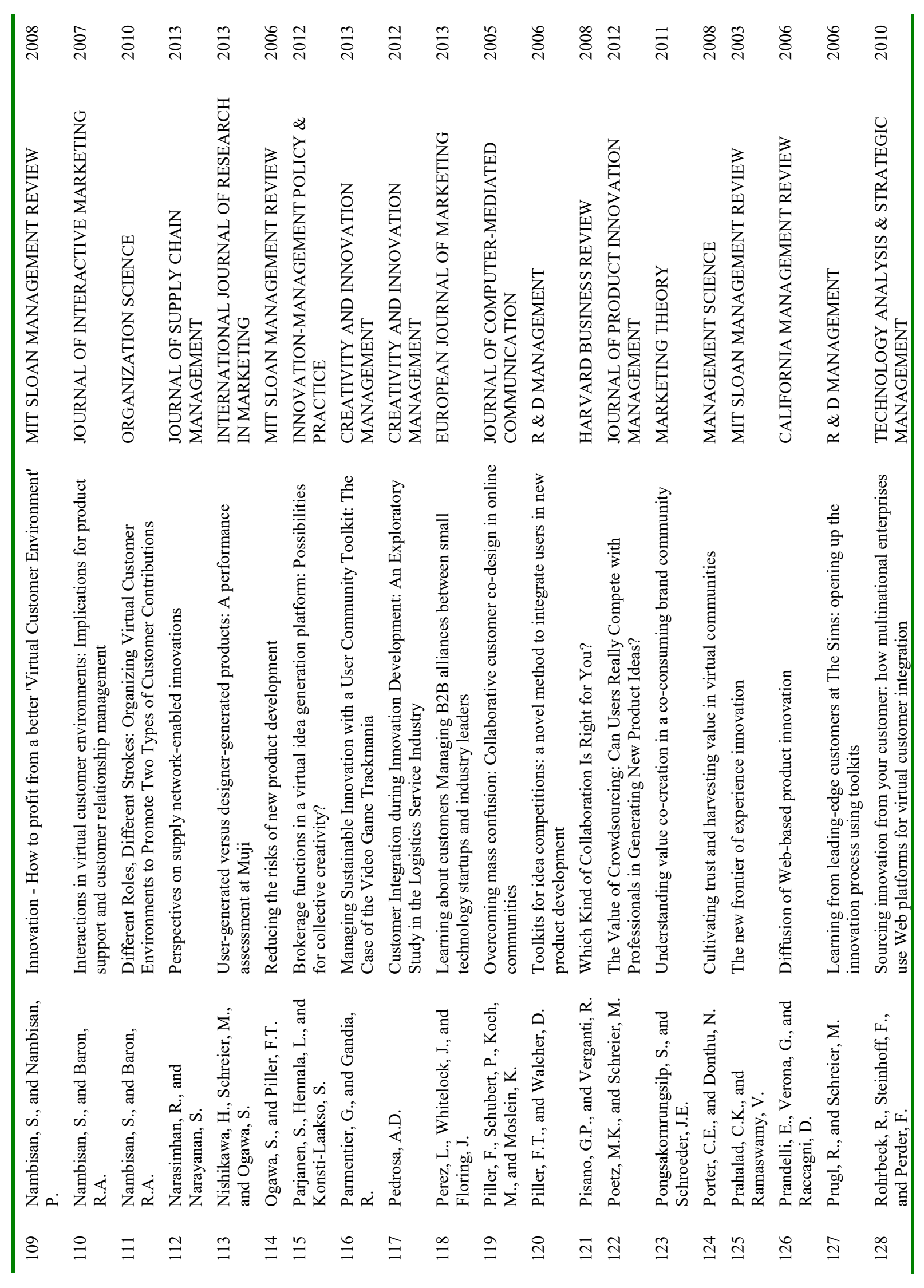




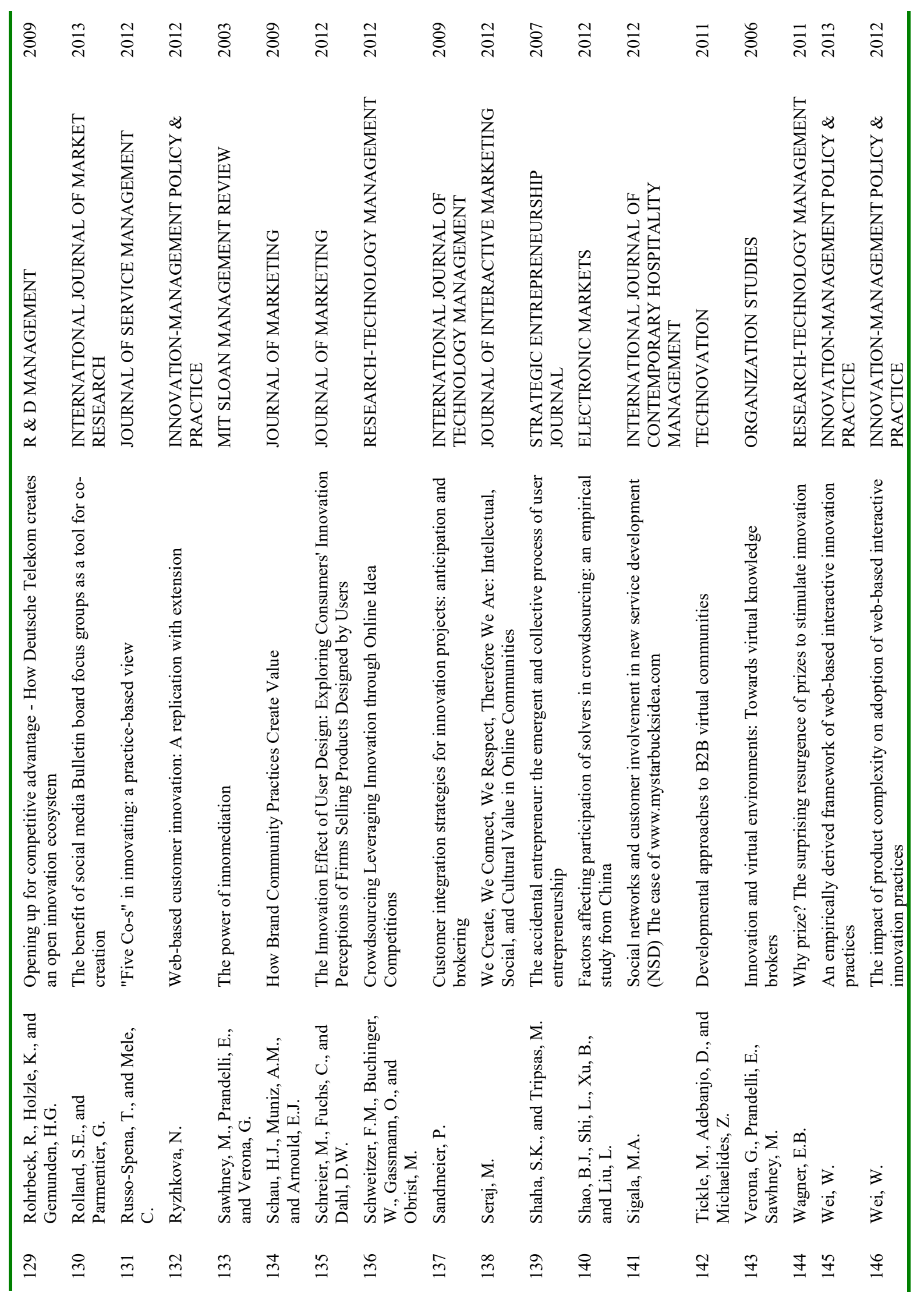




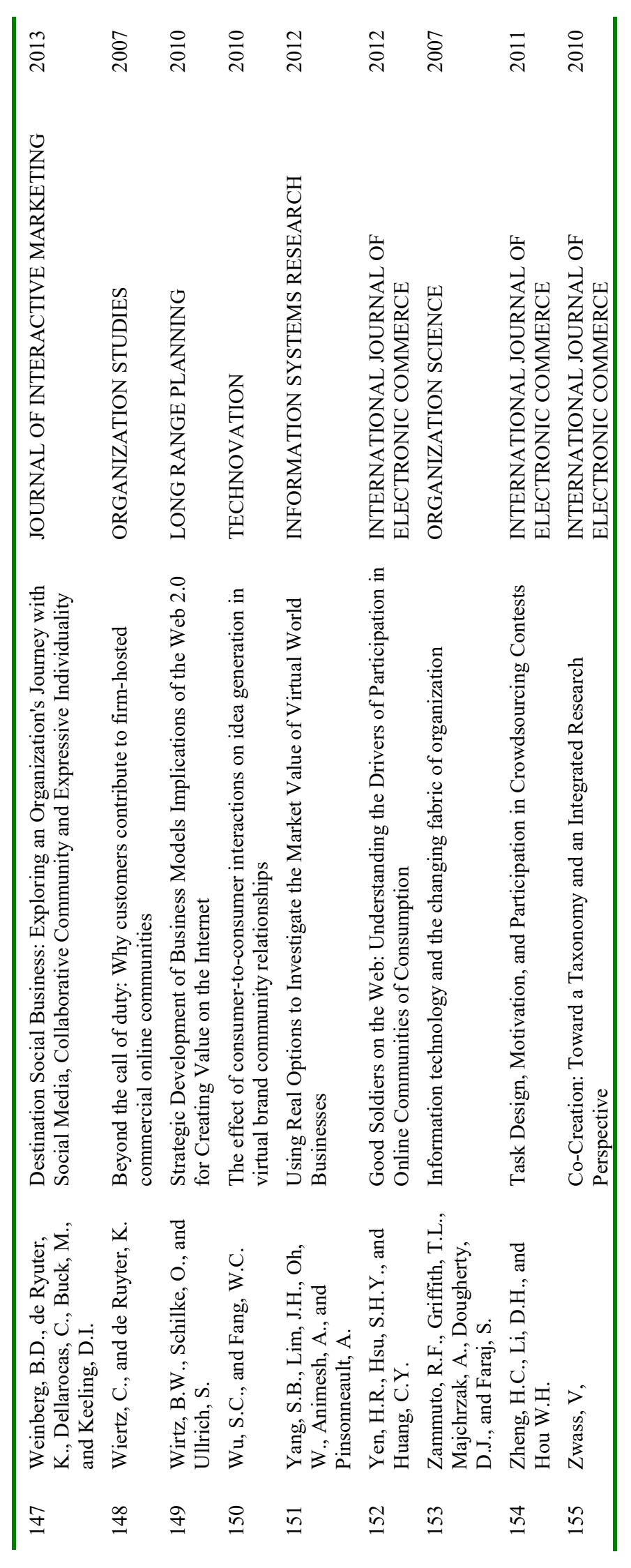

